\title{
UN TYPE PARTICULIER DE MONUMENTS FUNÉRAIRES : LES «PYRAMIDIONS» DES NÉCROPOLES GALLO-ROMAINES DE DIJON
}

\author{
par Hervé JOUBEAUX
}

Les archéologues du XıXe siècle ont dénommé "pyramidions" une série d'une quarantaine de monuments funéraires provenant des nécropoles gallo-romaines de Dijon. Taillés dans un calcaire local, ils ont la forme d'un obélisque et portent une épitaphe mentionnant le nom du défunt, souvent accompagné d'une brève formule fu

La concentration des pyramidions à Dijon et dans ses environs, les caractéristiques de l'onomastique et de l'epigraphie conduisent à supposer que ce type de monuments a pu avoir son origine dans la région lingone, pîu -être dès l'époque de La Tène.

The archaeologists of the XIXth century named "pyramidions» a set of about forty tombstones found in the 6...ilo-Roman necropolis of Dijon. Hewn in a local limestone, these obelisk-shaped monuments bear an epitaph cimprising the name of the deceased and, often, a short funerary phrase which makes it possible to date them between the second half of the Ist and the beginning of the IIIrd century A. D.

The concentration of "pyramidions" at Dijon and in the surrounding area, their epigraphical and onomastical features lead to believe that these monuments may originate in the Lingone area, perhaps slarting in the La Tene period.

Les monuments funéraires mis au jour à diverses époques dans les nécropoles gallo-romaines de Dijon peuvent être répartis en trois catégories. Outre les grands monuments - connus seulement par des fragments remployés généralement dans le rempart du Bas-Empire - et des stèles monolithes figurées ${ }^{1}$,

1 La plupart des monuments de ces deux catégories, conservés au Musée archéologique de Dijon, sont inventoriés dans Deyts (1976). Quelques stèles cependant sont conservées au Musée des Antiquités nationales de Saint-Germain-en-Laye. C'est également entre ces deux musées que sont répartis les pyramidions conservés. Nous remercions $M^{\text {me }}$ Jeanlin, alors convervatrice du Musée archéologique de Dijon et M. Joffroy $(\dagger)$, conservateur en chef du Musée des Antiquités nationales de Saint-Germain-en-Laye, qui nous ont autorisé à étudier et à photographier ces objets, ainsi que Mlle Beck, conservatrice au Musée des Antiquités nationales de Saint-en-Germain-en-Laye, qui nous y a accueilli. une série particulière est constituée par les monuments dénommés "pyramidions" par les archéologues locaux du XIX s. ${ }^{2}$.

Cet ensemble numériquement important - une quarantaine d'exemplaires inscrits et plusieurs dizaines anépigraphes - n'a fait l'objet d'aucune étude récente : la publication du Corpus Inscriptionum Latinarum a en effet marqué à la fois le couronnement et le terme de l'engouement des érudits pour ces objets qui retenaient alors l'attention unique-

2 Nous avons conservé par commodité ce terme localement usuel mais quelque peu impropre, ces monuments ayant moins la forme d'une petite pyramide que d'un obélisque et le mot "pyramidion" ne désignant que "la petite pyramide quadrangulaire qui termine les obélisques" (Littré). Quelques auteurs anciens utilisent d'ailleurs parfois les termes "obélisque» ou "aiguille». 
ment par leur intérêt épigraphique. C'est pourquoi il nous a paru intéressant de définir les caractéristiques de ce type bien distinct des autres monuments funéraires locaux, de dresser l'inventaire des exemplaires inscrits trouvés à Dijon et de poser le problème de l'origine de ce type et de son développement qui n'a pas d'équivalent dans les autres nécropoles gallo-romaines connues.

\section{PROVENANCE ET CONTEXTE}

Tous les pyramidions dijonnais trouvés in situ proviennent de la zone de sépultures située de part et d'autre de la voie romaine de Chalon-sur-Saône à Langres (fig. 1). C'est d'ailleurs dans ce secteur, utilisé comme nécropole surtout entre le milieu du $\mathrm{I}^{\text {er }} \mathrm{s}$. après J.-C. et la construction du castrum, qui eut vraisemblablement lieu dans le courant du III $^{\mathrm{e}} \mathrm{s}$., qu'ont été retrouvés presque tous les monuments funéraires de Dijon, en dehors de ceux remployés dans la construction des murs du castrum. Il est donc possible que ces derniers, et parmi eux les pyramidions $\mathrm{n}^{\mathrm{os}} 3,4,5,11,15,16$ (?), 20 et 30 (?), aient été primitivement dressés dans le mème secteur.

On possède très peu de renseignements sur le contexte archéologique des pyramidions découverts in situ. Il s'agit pour la plupart de trouvailles anciennes et fortuites qui n'ont pas fait l'objet d'observations précises : c'est en particulier le cas de l'ensemble de monuments provenant du lieu-dit Les Poussots $\left(\mathrm{n}^{\text {os }} 2,6,9,10,17,22,25,29,37\right)$. On sait seulement que certains signalaient des sépultures groupées ( $n^{\text {os }} 1,7,14,21,23$ et 33 par exemple) et pouvaient voisiner avec des stèles figurées $\left(\mathrm{n}^{\text {os }} 24,26\right.$ et $31 ; 32$ et $34 ; 38$, etc.). Les $\mathrm{n}^{\text {os }} 12,13,36$ et peutêtre 35 et 38 étaient associés à des sépultures par inhumation; il s'agissait pour le $\mathrm{n}^{\prime \prime} 35$ d'une sépulture d'enfant. Seul le $\mathrm{n}^{\prime} 28$ paraît avoir signalé une sépulture par incinération, mais il faut remarquer que, d'une manière générale, les incinèrations sont beaucoup plus rarement observées que les inhumations lors de ces découvertes fortuites. On peut donc se demander si les nombreux monuments auprès desquels on n'a signalé aucune sépulture n'étaient pas pour beaucoup associés à une incinération.

Les seules indications un peu plus développées concernent les pyramidions $n^{\text {os }} 12$ et 13 qui, associés à deux autres anépigraphes, auraient été "posés aux angles de la même sépulture" (Catal. musée CACO, 1894 , p. 54).

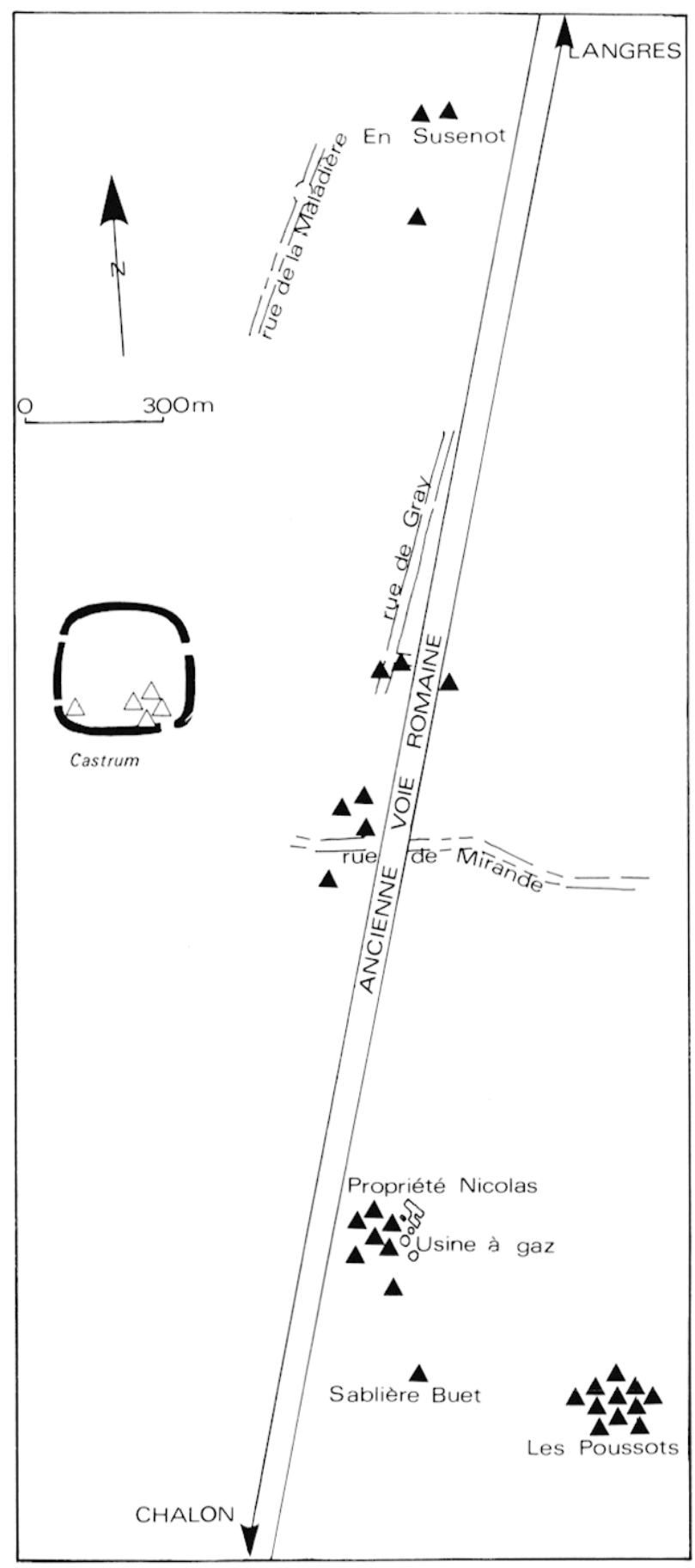

Pyramidions $\boldsymbol{\Delta}$ in situ $\triangle$ en remploi

Fig. 1 - Lieux de provenance des pyramidions découverts à Dijon.

\section{LES PYRAMIDIONS FUNERAIRES HORS DE DIJON}

En dehors des exemples dijonnais, on connait un certain nombre de monuments analogues provenant pour la plupart de localités situées à moins de 
$100 \mathrm{~km}$ de Iijon (fig. 2). Quatre proviennent de Langres $^{3}$, deux de Til-Châtel ${ }^{4}$ et un de chacun des sites suivants : Chàtillon-sur-Seine ${ }^{5}$, Aignay-le-Duc ${ }^{6}$. Alise-Sainte-Reine ${ }^{7}$, Étaules ${ }^{8}$, Mirebeau ${ }^{9}$ et Mesmont ${ }^{10}$. On en aurait également découvert quelquesuns dans la nécropole de Marsannay-la-Côte ${ }^{11}$. On remarque que les plus nombreux ont été trouvés à proximité de la grande voie reliant Chalon-sur-Saône à Langres, de part et d'autre de laquelle avaient été dressés les exemplaires dijonnais. On peut donc penser que cet important axe nord-sud a eu un rôle dans la diffusion de ce type de monument.

A l'extérieur des territoires des Lingons et des Mandubiens, auxquels se rattachent tous les exemples que nous venons de citer, nous ne connaissons que très peu de monuments comparables aux pyramidions à la fois par leurs caractéristiques morphologiques et épigraphiques, leur fonction et leur datation ${ }^{12}:$ on en a récemment découvert un à Martigny (Suisse) ${ }^{13}$; il en existe également quelquesuns à Metz ${ }^{14}$. Mais dans le premier cas il semble qu'il s'agisse d'un exemplaire isolé; quant aux exemples messins, ils ne paraissent pas permettre de déterminer, comme on l'a fait pour la région dijonnaise, une série précise et distincte, les monuments funéraires de la région messine appartenant à des types beaucoup plus variés et qui se sont sans doute largement interpénétrés. On pourrait citer également tel exemplaire d'Autun ${ }^{15}$ ou de Saintes ${ }^{16}$, mais le

3 CIL XIII 5726, 5753 et 5820; le quatrième n'est pas répertorié au $C I L$, musée Saint-Didier de Langres.

4 CIL XIII, 5628 et 5629. Musée archéologique de Dijon.

5 Inédit? Musée archéologique de Châtillon-sur-Seine.

6 CIL XIII, 2888. Perdu?

7 CIL XIII, 2881. Musée municipal d'Alise-SainteReine.

8 CIL XIII, 5620. Musée archéologique de Dijon.

9 CIL XIII, 5617. Perdu?

10 CIL XIII, 5608. Musée archéologique de Dijon.

11 Mémoires de la Commission des Antiquités de la Côted'Or (Mem. CACO), 9, 1874-1877, p. Lvili-l.Ix (Lory). Ces pyramidions ne paraissent pas avoir été conservés. Deux autres, sans provenance, sont conservés dans la cour du Musée archéologique de Dijon.

12 Toutefois, les monuments non figurés étant rarement publiés et surtout rarement photographiés, un certain nombre d'entre eux a pu échapper à nos recherches.

13 Annales Valaisannes, 1981, p. 104-105. Musée archéologique de la fondation Pierre-Gianadda à Martigny.

14 Linckenheld, 1927, en particulier pl. II, fig. 5 $=$ CII XIII. 4418 . Autun.

15 CIL XIII. 2763. Musée lapidaire Saint-.Nicolas à

I6 Wuilleumier. 1963. p. 52, n" 150. Musée archéologique de Saintes.

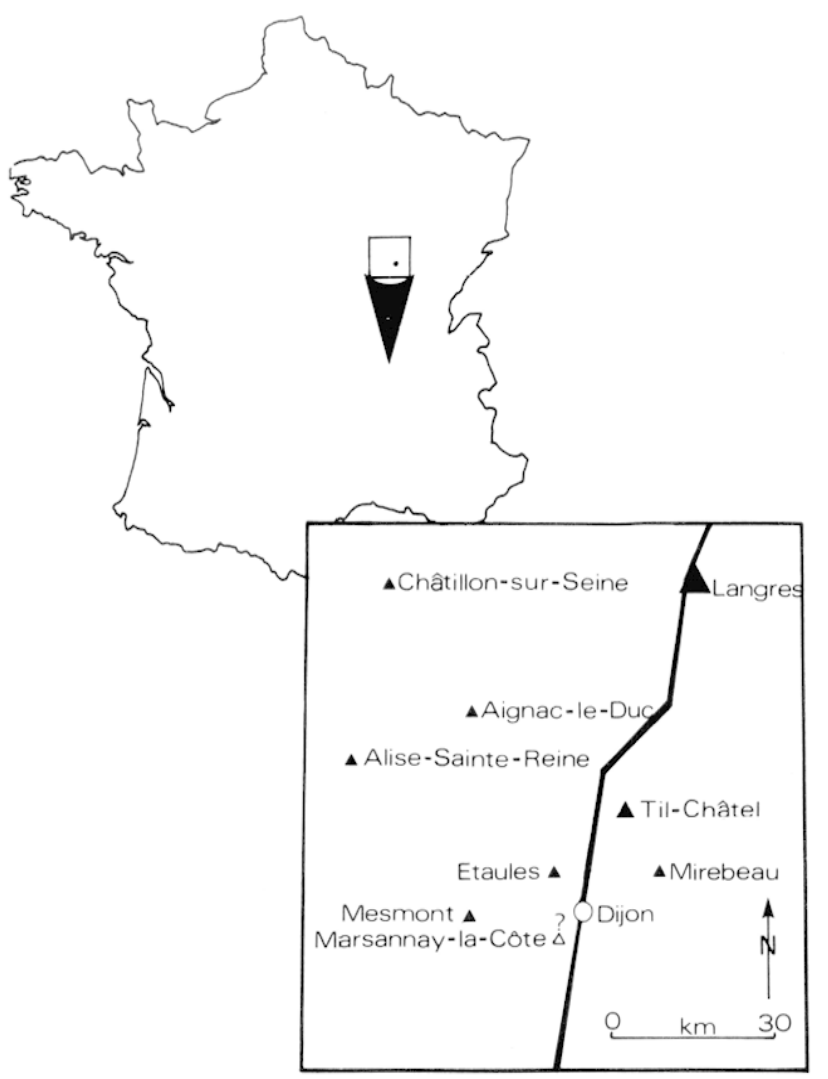

Fig. 2 - Lieux de provenance des pyramidions découverts en dehors de Dijon.

premier, couronné d'un véritable "pyramidion " et le second, surmonté d'une sorte de piédouche, nous paraissent s'éloigner de la simplicité morphologique extrème qui est une des caractéristiques, constante et essentielle, de la sèrie dijonnaise. Par ailleurs, il semble qu'il s'agisse là aussi de deux exemples isolés dans leur contexte local.

\section{DESCRIPTION}

Les pyramidions sc présentent sous la forme de monolithes à quatre faces, plus hauts que larges. Pour les exemplaires dijonnais complets, la hauteur est comprise entre 0,44 et $1,45 \mathrm{~m}$; la hauteur moyenne est d'environ $0,90 \mathrm{~m}$. Mais le pyramidion de Mesmont est haut de $2,12 \mathrm{~m}$ et celui d'AliseSainte-Reine atteint $2,30 \mathrm{~m}$. La base est généralement plus large que le sommet; seul le $\mathrm{n}^{0} 23$ est à peu près parallélépipèdique. Deux faces opposées sont en général plus larges que les deux autres: lorsqu'une inscription est gravée, elle l'est générale- 
ment sur une des faces larges; toutefois, sur les $\mathrm{n}^{\mathrm{os}} 19,25,33$ et 34 , l'inscription se trouve sur une des faces étroites. On notera par ailleurs le cas particulier du n ${ }^{0} 11$ qui paraît avoir été inscrit sur deux faces; mais il n'est connu que par un dessin qui ne permet pas de savoir s'il s'agit de deux faces contiguës ou opposées. Le sommet et la base sont plus ou moins plans et horizontaux, à deux exceptions près : le sommet du $n^{\circ} 32$ comporte une petite cuvette qui parait avoir été pratiquée intentionnellement; la base du $\mathrm{n}^{\circ} 16$ était, d'après le dessin que nous en connaissons, arrondie. une partie de la sculpture funéraire des Bolards (Nuits-Saints-Georges, Côte-d'Or) (Deyts, 1982). Il semble par contre qu'aucune des sculptures galloromaines de provenance locale conservées au Musée archéologique de Dijon n'ait été réalisée dans ce matériau ${ }^{20}$.

La qualité de la taille de la pierre paraît avoir été très variable d'un exemplaire à l'autre, mais la plupart sont très usés et abîmés. Il semble qu'ils aient été simplement taillés à la scie : des traces en sont encore visibles sur ceux dont la surface n'est pas trop érodée. Les angles paraissent avoir été laissés vifs. Il est possible que, dans certains cas, la face principale, destinée à recevoir l'inscription, ait été aplanie.

\section{CATALOGUE DES TRENTE-NEUF PYRAMIDIONS DECOUVERTS Ȧ DIJON}

Vingt-cinq sont conservés au Musée archéologique de Dijon (un est égaré), cinq au Musée des Antiquités nationales de Saint-Germain-en-Laye, neuf sont perdus.

Chaque notice indique :

- le lieu et les circonstances de la découverte, l'état de conservation, le matériau, les dimensions en $\mathrm{cm}$;

- les caractéristiques générales de l'inscription;

- le texte de l'inscription, sa restitution, le commentaire épigraphique ligne à ligne ;

- le commentaire onomastique;

- le lieu de conservation, la bibliographie.

1 Découvert dans la propriété Nicolas, entre le Cours du Parc et la rue de Longvic, vers 1866-1867, dans des circonstances inconnues, avec d'autres monuments funéraires, notamment les pyramidions $\mathrm{n}^{\mathrm{os}} 7,14,21,23$ et 33 .

Partie supérieure d'un pyramidion, assez soigneusement taillée. Pierre calcaire. Hauteur conservée : 25 ; largeur maximale conservée : 19 ; largeur au sommet : 16,5 ; épaisseur maximale conservée : 12 ; épaisseur au sommet : 11.

Inscription dont deux lignes et le début d'une troisième sont conservés.

Écriture de bonne qualité. Gravure large et profonde. Hauteur des lettres : 2,9 à $3,5 \mathrm{~cm}$.

20 Deyts, 1976, avant-propos (le matériau). 


\section{DIS / MANIBV[s] / SV[...] \\ Dis Manibus $\mathrm{Su} . .$.}

l. 3 : d'après la largeur des deux premières lettres, cette ligne n'en comportait que cinq ou six.

Musée archéologique de Dijon, inv. 239.

Lejay, $1889, \mathrm{n}^{\circ} 138$ - Calal. Musée CACO, $1894, \mathrm{n}^{\circ} 239$.

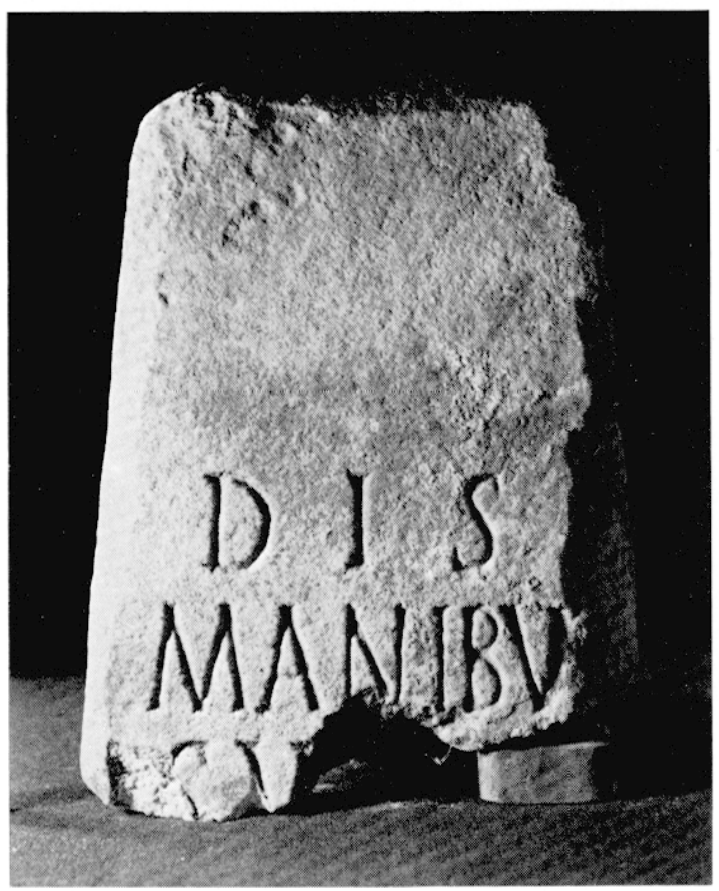

2 Découvert au lieu-dit Les Poussots. Date, circonstances et contexte inconnus.

Partie supérieure d'un pyramidion, soigneusement taillé. Pierre calcaire. Hauteur conservée : 24,5 ; largeur maximale conservée: 18; épaisseur maximale conservée : 16 .

Inscription sur trois lignes, peut-être complète. Écriture médiocre. Gravure assez profonde. Hauteur des lettres : 2 à $4 \mathrm{~cm}$.

\section{DM. / AVITIAN / DRIBIONOS D(is) M(anibus) Avitian(us) Dribionos}

l. 1 : peut-être un point après le $M$;

l. 1 et 2 : point triangulaire entre les deux lignes;

l. 2 : un A à barre oblique, le second A sans barre;

l. 2 et $3:$ la hauteur des lettres est très irrégulière.

Avitianus: cognomen latin (Kajanto, 1965, p. 109 et 304) connu dans toutes les régions de Gaule et de Germanie (neuf mentions dans les tomes XII et XIII du $C I L$ ). Il existait peut-être sur une autre inscription de Dijon: Saci/ro] (?) Avilli]ani (?) fi(lius) (CIL, XIII, 5560). C'est aussi le nom d'un potier de Gaule du Sud du Ir s. (Oswald, 1931, p. 33).

Dribionos : ce nom ne paraît pas connu ailleurs en Gaule. Il semble formé sur la même racine que Driburo, nom connu à Lyon (Rhône) (CIL XIII, 1985).

Musée des Antiquités nationales de SaintGermain-en-Laye, inv. 50492.

Desjardins, 1880 , p. 135 - Lejay, $1889, \mathrm{n}^{\circ} 126$

- Mowat, 1890, p. 423, no $44-C I L$ XIII, 5494 - Reinach, 1917, p. 229, n 50492.

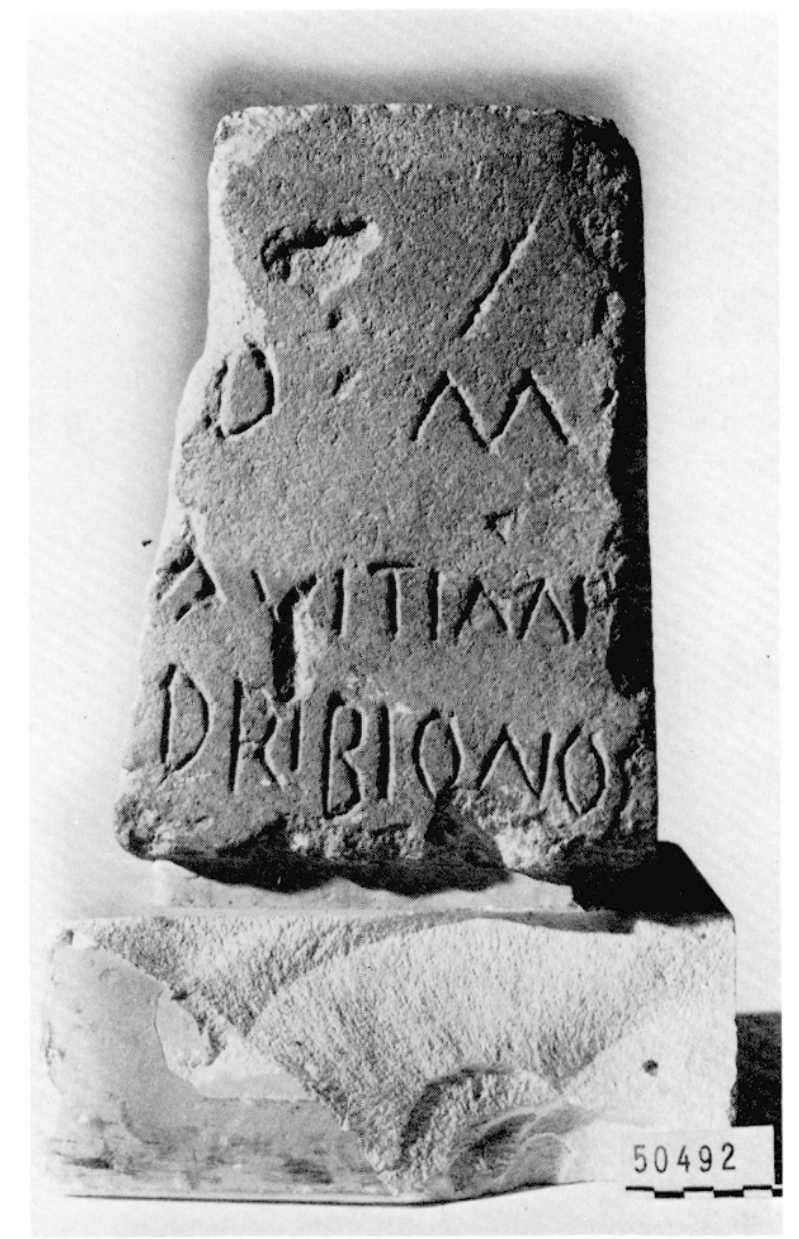

3 Découvert à l'emplacement du Collège des Godrans, actuellement entre la rue de l'École-de-Droit et la rue du Petit-Potet, vers 1581-1585, au moment de la construction du collège, en remploi dans le mur du casirum.

Nature de la pierre et dimensions inconnues. Inscription sur trois lignes, qui serait complète. 


\section{D.M. / HILARVS DR. / C. CAE. $D$ (is) M(anibus) Hilarus...}

I. 2 et $3:$ la fin de la deuxième et la troisième lignes ont sans doute été mal relevées. Dans son index, le CIL propose $\mathrm{Dr} / \mathrm{u}] \mathrm{ccae}$, sans justifier cette restitution.

Hilarus : cognomen latin très répandu (Kajanto, 1965 , p. 29), connu en Gaule à Langres (HauteMarne) (CIL XIII, 5748 et 11584), Briord (Ain) (CIL XIII, 2469) et trois fois à Lyon (Rhône), dont une avec la variante Hylarus (CIL XIII, 1873, 2202 et 2300). Ce serait un cognomen religieux, lié au culte de la Grande-Mère (Hatt, 1951, p. 52-54 et 273).

Perdu.

Richard, 1585, folio 42 - Belloguet, 1851, p. 169 - Lejay, 1889 , n $90-$ CIL XIII, 5519 .

4 Découvert à l'emplacement de l'Hôtel Lorin, actuellement 7 , rue Hernoux, avant 1863 , dans des circonstances inconnues, en remploi dans le mur du castrum.

État de conservation et nature de la pierre inconnus. Hauteur : 1,45; largeur à la base : 0,40 ; largeur au sommet : 0,16 .

Inscription sur deux lignes.

\section{M. / MAGIAN}

$D($ is) M(anibus) Magian(us ou i)

Magianus: cognomen latin (Kajanto, 1965, p. 149) connu en Gaule sur une inscription de Baden (Canton d'Argovie, Suisse) (CIL XIII, 5233).

Musée archéologique de Dijon, inv. 229. Égaré. Lejay, 1889, no 66 - Catal. Musée CACO, $\mathrm{n}^{\circ} 229-C I L$ XIII, 5531 .

5 Découvert à l'emplacement du Collège des Godrans, actuellement entre la rue de l'École-de-Droit et la rue du Petit-Potet, sans doute vers 1581-1585, au moment de la construction du collège, en remploi dans le mur d'une tour du castrum.

Pyramidion qui paraît soigneusement taillé. Nature de la pierre et dimensions inconnues.

Inscription sur trois lignes. L'écriture paraît de bonne qualité.

D M / REBRICA / SEDATIFIL $D$ (is) M(anibus) Rebrica Sedati fil(ia).

1. 3 : pas de ponctuation et séparation très étroite entre Sedati et fil(ia).

Rebrica : nom connu par deux inscriptions de la région de Belley (Ain) (CIL XIII, 2516 et 2531). On connaît également Rebricus à Soulosse (Vosges) (CIL XIII, 4700), Langres (Haute-Marne) (CIL XIII, 5838) et sur une autre inscription de Dijon (CIL XIII, 5487); toujours à Dijon, variante Ribricus (CIL XIII, 5534).

Sedatus : cognomen latin (Kajanto, 1965, p. 262), cité dix autres fois dans le tome XIII du CIL. A l'exception d'une inscription de Bordeaux (Gironde) (CIL XIII, 846), toutes proviennent de la Gaule de l'Est et de Germanie. On notera particulièrement la présence de ce nom à Autun (Saône-et-Loire) (CIL XIII, 2706), Langres (Haute-Marne) (CIL XIII, $11587)$ et Chalon-sur-Saône (Saône-et-Loire) (CIL XIII, 2618).

Perdu.

Legouz de Gerland, 1771, p. 144 et pl. XXVI, $\mathrm{n}^{\circ} 2$ - Lejay, $1889, \mathrm{n}^{\circ} 69-$ CIL XIII, 5551 .

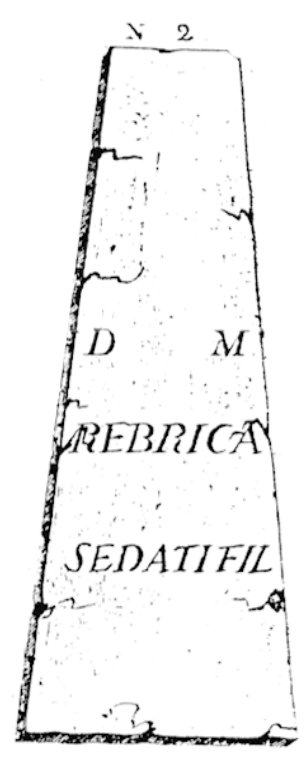

Dessin extrait de Legouz de Gerland, 1771. pl. $X X V I, n^{\circ} 2$.

6 Découvert au lieu-dit Les Poussots. Date, circonstances et contexte inconnus.

Pyramidion soigneusement taillé, mais la partie supéricurc cst extrêmement érodée. Pierre calcaire. Hauteur : 105; largeur à la base : 34; largeur au sommet : 14,5 ; épaisseur à la base $: 31$; épaisseur au sommet : 12 .

Inscription sur quatre lignes. Ecriture médiocre. Gravure très usée. Hauteur des lettres : 2,5 à $5 \mathrm{~cm}$.

D) M / REGALI / A[...]TER[...]LO / FI[li]O D(is) M(anibus) Regali A...ler...lo filio.

I. 2: E formé de deux barres verticales. La barre horizontale du A a été omise. L à barre tombante; 
1. 3 : on peut restituer une ou deux lettres entre le $\mathrm{A}$ et le T. E formé de deux barres verticales. On peut restituer une lettre entre le $\mathrm{R}$ et le $\mathrm{L}$. $\mathrm{L}$ à barre tombante:

1. 4 : il ne reste plus du $F$ que la barre verticale.

Regalis : cognomen latin (Kajanto, 1965, p. 18 et 316) répandu surtout dans l'Est de la Gaule. On le retrouve sur deux autres inscriptions de Dijon, provenant des murs du castrum (CIL XIII, 5553 et $5554)$ et sur une stèle funéraire de Langres (HauteMarne), également au datif (CIL XIII, 5695); c'est également le nom d'un potier de Lezoux (Puy-deDôme), connu de l'époque de Domitien à celle d'Antonin (Oswald, 1931, p. 259) et d'un potier de Rheinzabern (Rhénanie-Palatinat, RFA) de l'époque d'Antonin (Oswald, 1931, p. 260).

Le deuxième nom est difficile à restituer : il ne reste actuellement aucune trace des lettres manquantes. Ni Acterolo, proposé par Desjardins, ni Aslerolo, proposé par Mowat, ne sont des noms connus en Gaule et on pourrait peut-être restituer deux lettres entre le $\mathrm{A}$ et le $\mathrm{T}$. Par ailleurs, la terminaison en -o est étonnante pour un nom qui devrait être au génitif.

Musée des Antiquités nationales de SaintGermain-en-Laye, inv. 50489.

Desjardins, 1880, p. 136 - Lejay, 1889, n" 127

- Mowat, 1890, p. 422, n 40 - CIL XIIl, 5552 - Reinach, 1917, p. 229, no 50409 .

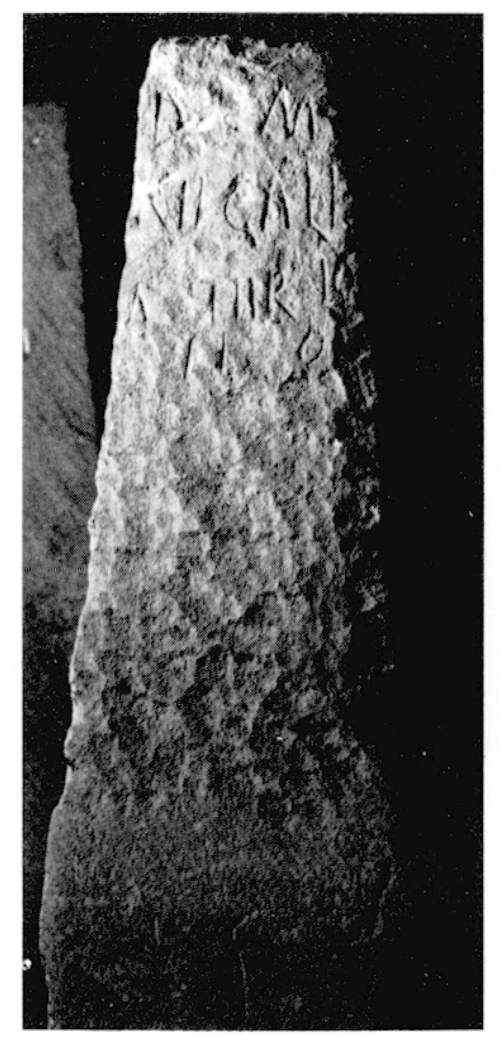

7 Découvert dans la propriété Nicolas; date, circonstances et contexte identiques à ceux du $n^{0} 1$.

Partie supérieure d'un pyramidion. Surface usée. Pierre calcaire. Hauteur conservée : 25 ; largeur maximale conservée : 15,5; largeur au sommet : 12 ; épaisseur maximale conservée : 13,5 ; épaisseur au sommet : 9,5 .

Inscription dont deux lignes sont conservées. Écriture de bonne qualité. La gravure, usée, devait être profonde et régulière. Hauteur des lettres : 3 à $4 \mathrm{~cm}$.

$$
\begin{gathered}
\text { D M / SAGE / [...] } \\
D(\text { is ) M(anibus) Sage ... }
\end{gathered}
$$

1. 2 : la barre horizontale du A a été omise. La barre verticale du $\mathrm{G}$ est très courte. Mowat avait d'ailleurs lu un C. La dernière lettre paraît être un $\mathrm{E}$ formé de deux barres verticales : la petite barre inférieure horizontale de la seconde paraît en effet s'arrêter juste avant la cassure. Il faudrait donc lire Sage ... et non Sagil ..., comme le proposaient Mowat et le CIL. Cependant la forme Sagil ... est connue (Evans, 1967, p. 80-81 et 251-252) alors que la forme Sage... ne l'est pas.

Musée archéologique de Dijon, inv. 240.

Lejay, 1889, n 65 - Mowat, 1890, p. 417, $\mathrm{n}^{\circ} 32$ - Catal. Musée CACO, 1894, n ${ }^{\circ} 240$ - CIL XIII, 5564 .

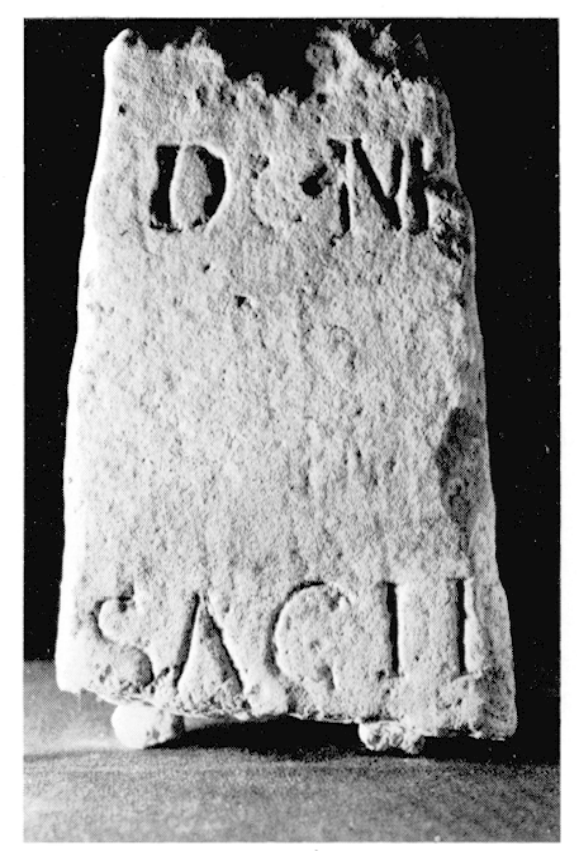

8 Découvert «à Dijon dans les sablières du grand cours Fleury, cours d'Ignace, allée de la Retraite" (Mém. CACO). Le cours Ignace et l'allée de la 
Retraite désignent la même artère, actuellement boulevard Voltaire, le long de laquelle ont été découvertes de nombreuses sépultures gallo-romaines; mais le cours Fleury était situé dans un autre quartier de Dijon, à l'écart des zones de sépultures. En 1846, dans des circonstances inconnues.

Nature de la pierre et dimensions inconnues.

Inscription peut-être complète, sur deux lignes.

$$
\begin{gathered}
\text { M.D. / IVLIVS } \\
\text { M(anibus) } D(\text { is) (?) Iulius. }
\end{gathered}
$$

1. 1 : la même abréviation $M . D$. se retrouve sur les $\mathrm{n}^{\text {os }} 9$ et 18 .

Iulius : gentilice latin fréquemment utilisé comme cognomen dans l'Est de la Gaule et en Germanie (dix mentions dans le tome XIII du CIL).

Perdu.

Mém. CACO, 2, 1817, p. LII (Rossignol) - CIL $\mathrm{XIII}, 5520$.

9 Découvert au lieu-dit Les Poussots. Date, circonstances et contexte inconnus.

Partie supérieure d'un pyramidion assez soigneusement taillée mais érodée. Pierre calcaire. Hauteur conservée : 27 ; largeur maximale conservée : 17 ; largeur au sommet: 14,5; épaisseur maximale conservée : 15 ; épaisseur au sommet: 12,5 .

Inscription dont une ligne et quelques traces d'une seconde sont conservées. Ecriture de qualité moyenne. Gravure large et profonde. Hauteur des lettres : 3,5 et $3,2 \mathrm{~cm}$.

$$
\begin{gathered}
\text { M D } /[\ldots] \\
M \text { (anibus) } D(\text { is })(?) \ldots
\end{gathered}
$$

1. 1 : la restitution $M$ (onumentum) $D$ (is) $M$ (anibus), proposée par Lejay, est peu vraisemblable car il faudrait admettre que le second $\mathbf{M}$ aurait été gravé sur la deuxième ligne;

1. 2 : on distingue seulement la partie supérieure d'une barre oblique descendant vers la droite et celle d'une barre verticale près du bord droit.

Musée archéologique de Dijon, inv. 243.

Lejay, 1889, no 125 - Mowat, 1890, p. 418, $\mathrm{n}^{\circ} 33$ - Calal. Musée CACO, 1894, n 243; CIL XIII, 5589².

21 Le $C I L$ répertorie sous le no 5542 un fragment de pyramidion portant l'inscription MD / IM / [...], qui correspond à un des dessins de Caumont, 1870. Nous n'avons pas retrouvé au Musée archéologique de Dijon ce fragment qui devrait s'y trouver. S'agit-il de notre no 9 , qui serait recassé? Les dimensions pourraient correspondre.

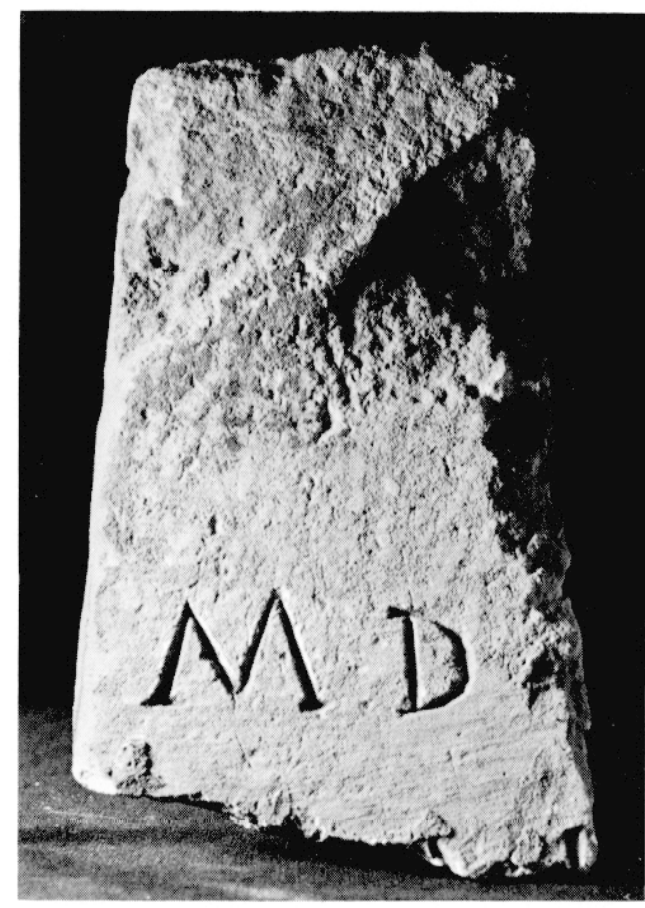

10 Découvert au lieu-dit Les Poussots. Date, circonstances et contexte inconnus.

Partie supérieure d'un pyramidion assez grossièrement taillée et très érodée ; un important éclat sur la face principale a endommagé plusieurs lettres de l'inscription. Pierre calcaire. Hauteur conservée : 31 ; largeur maximale conservée : 17,5; largeur au sommet: 15 ; épaisseur maximale conservée : 16 ; épaisseur au sommet : 14 .

Inscription sur quatre lignes, qui paraît complète. Écriture médiocre, à l'exception du D initial. La profondeur et la régularité de la gravure diffèrent également entre la première ligne et les suivantes, beaucoup moins soignées. Hauteur des lettres : 2,7 à $4,2 \mathrm{~cm}$.

$$
\begin{gathered}
\text { D / CAR[a]N / TINUS /FI } \\
\text { D(is Manibus) (?) Carantinus fi(lius). }
\end{gathered}
$$

1. 1 : le M qui devrait suivre le D n'a jamais été gravé;

1. 2 : la barre transversale du premier $\mathrm{A}$ a été omise. La lettre placée entre le $\mathrm{R}$ et le $\mathrm{N}$ est probablement un second $\mathrm{A}$, dont on distingue la partie inférieure. On attendrait un second nom propre, au génitif, entre Carantinus et filius.

Carantinus : nom d'un potier de Lezoux (Puyde-Dôme) de la période Domitien-Trajan (Oswald, 1931, p. 60). Nom composé sur la racine caro- dont la forme carant- est fréquemment attestée (Evans, 1967, p. 162-166) : on note particulièrement Carantus à Dijon (Lejay, 1889, $\mathrm{n}^{\circ} 88$ ). 
Musée archéologique de Dijon, inv. 241.

Rossignol, 1854, p. 569 - Caumont, 1870, p. 521 - Lejay, 1889, $\mathrm{n}^{\circ} 123$ - Mowat, 1890, p. $418, \mathrm{n}^{\circ} 34-$ Calal. Musée CACO, n 241 CIL XIII, 5503 .

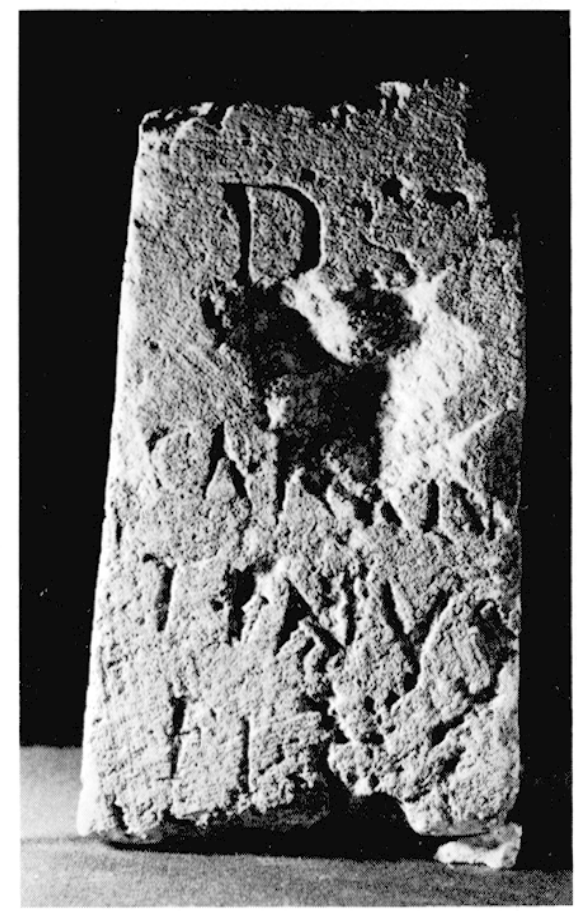

11 Découvert à Dijon, avant 1771, dans des circonstances inconnues, en remploi dans le mur du castrum.

Pyramidion paraissant assez soigneusement taillé; peut-être une cassure à mi-hauteur. Nature de la pierre inconnue. Largeur à la base : $\pm 22,4$; largeur au sommet : $\pm 16,8$

Inscription sur deux faces (contiguës ou opposées?); six lignes sur une face, trois lignes sur l'autre. L'écriture paraît régulière, bien que Legouz précise : "Les caractères sont mal formés».

A) D M / MIM / OPRI / VAII / ARRIC / IIL $D$ (is) $M$ (anibus) $M<e>m o$ (riae) (?) Priva $<l>i$ (?) Arric(i) $<f>$ il( ii) (?).

B)

$$
\text { CAMBAD / AMB / DIC }
$$

A) 1. 2: I pour E?

1. $4: \mathrm{A}$ à barre tombante. I pour $\mathrm{T}$ ?

I. 5: A à barre tombante;

1. 6 : I pour $\mathrm{F}$ ? L à barre oblique.

B) Cette partie de l'inscription a sans doute été mal lue. Elle semble avoir comporté au moins un nom propre. S'agit-il, comme le suggérait Lejay, de celui du curateur?

I. 1 : deux A à barre tombante;

1. 2: A à barre tombante.

Privatus : cognomen latin (Kajanto, 1965, p. 82 et 315 ) courant en Gaule (sept mentions dans le tome XIII du CIL et nom de trois potiers de La Graufesenque (Aveyron), Lezoux (Puy-de-Dôme) et Rheinzabern (Rhénanie-Palatinat, RFA) de la seconde moitié du ${ }^{\text {er }} \mathrm{s}$. et de la première moitié du II $^{e} \mathrm{~s}$. (Oswald, 1931, p. 252).

Arricus : ce nom n'apparaît ni dans les cognomina latins ni dans les listes de noms gaulois. On connaît Aricus, potier de Lezoux (Puy-de-Dôme) et Lubié (Allier) sous Hadrien et Antonin (Oswald, 1931, p. 23).

Cambad...? : nom à rapprocher de Cambo, connu à Landau (Rhénanie-Palatinat, RFA) (CIL XIII, 6091) et près de Metz (Moselle) (CIL XI11, 4627) et de Cambuxa, connu à Auch (Gers) (CIL XIII, 449). Sur Cambo- et ses dérivés, voir Dottin, 1920 , p. 240 et Evans, 1967, p. 320-322.

Perdu.

Legouz de Gerland, 1771, p. 125-126 et pl. XVIII, $\mathrm{n}^{\circ} 2$ - Lejay, $1889, \mathrm{n}^{\circ} 107$ CIL XIII, 5550 .

Dessin extrait de Legouz de Gerland, 1771, pl. XVIII, no 2.

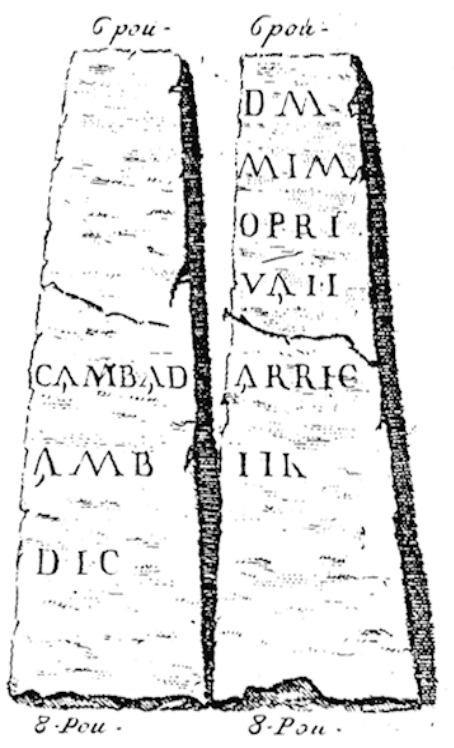

12 Découvert à l'angle de la rue de Gray et de la rue de Metz, en avril 1889, au cours de fouilles surveillées par H. Joliet, membre de la Commission des Antiquités de la Côte-d'Or, avec des sépultures par inhumation. Ce pyramidion, avec le $\mathrm{n}^{\circ} 13$ et 
deux autres, anépigraphes, "étaient posés aux angles de la même sépulture» (Catal. Musée CACO).

Pyramidion assez soigneusement taillé mais érodé. Pierre calcaire. Hauteur : 88,5 ; largeur à la base : 30 ; largeur au sommet : 14,5 ; épaisseur à la base : 24,5 ; épaisseur au sommet : 11 .

Inscription sur trois lignes, complétée par l'inscription du $n^{0} 13$. Écriture médiocre. Gravure étroite et peu profonde. Hauteur des lettres : 4,2 à $5,2 \mathrm{~cm}$.

\section{DIS / MANI / BVS Dis Manibus.}

1. 2 : A à barre tombante. Une barre identique a été placée par erreur entre les deux premières barres du $\mathrm{N}$;

1. 3 : la boucle inférieure du B n'est pas fermée.

Musée archéologique de Dijon, inv. 230.

Mém. CACO, 12, 1889-1895, p. xxvi1-XxviII (Joliet) - Catal. Musée CACO, $\mathrm{n}^{\circ} 230-C I L$ XIII, 5587.

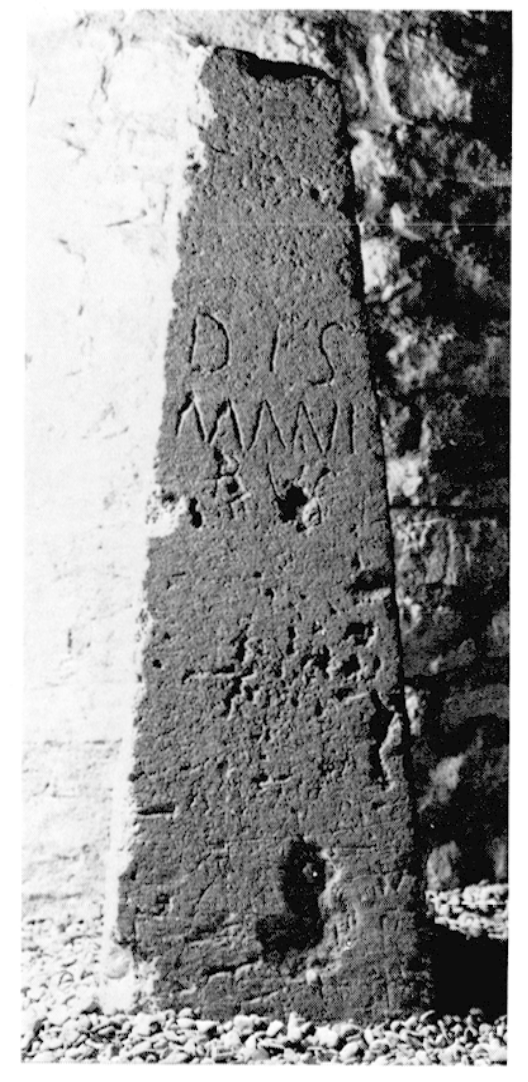

13 Découvert avec le précédent et dans les mêmes circonstances.

Pyramidion très soigneusement taillé. Plusieurs éclats le long des arêtes, dont l'un a détruit quelques lettres de l'inscription. Pierre calcaire. Hauteur: 121 ; largeur à la base : 34 ; largeur au sommet : 15 ; épaisseur à la base : 29,5 ; épaisseur au sommet: 12,5 .

Inscription sur quatre lignes. Écriture identique à celle du $n^{\circ} 12$. Gravure étroite et peu profonde. Hauteur des lettres : 3,8 à $4,2 \mathrm{~cm}$.

\section{MON[i]M / ENTV[m] / ROXTANI / PETRVLI.I Monimentum Roxtani Petrulli.}

1. 1: l'extrémité supérieure du deuxième $M$ est visible. Le I a peut-être été omis; il n'y a pas assez de place pour un $\mathrm{V}$;

1. 2 : $\mathrm{E}$ formé de deux barres verticales;

l. 3 : A à barre tombante. Le dernier jambage du $\mathrm{N}$ est détaché ;

I. 4 : $\mathrm{E}$ formé de deux barres verticales. Deux $\mathrm{L}$ à barre oblique.

Roxtanus : ce nom ne paraît pas connu ailleurs en Gaule mais il peut être rapproché de $R o x t u$..., à Autun (Saône-et-Loire) (CIL XIII, 2755 et XIII, IV, p. 30) et Roxlanorix, à Entrains (Nièvre) (CIL XIII, $11269)$.

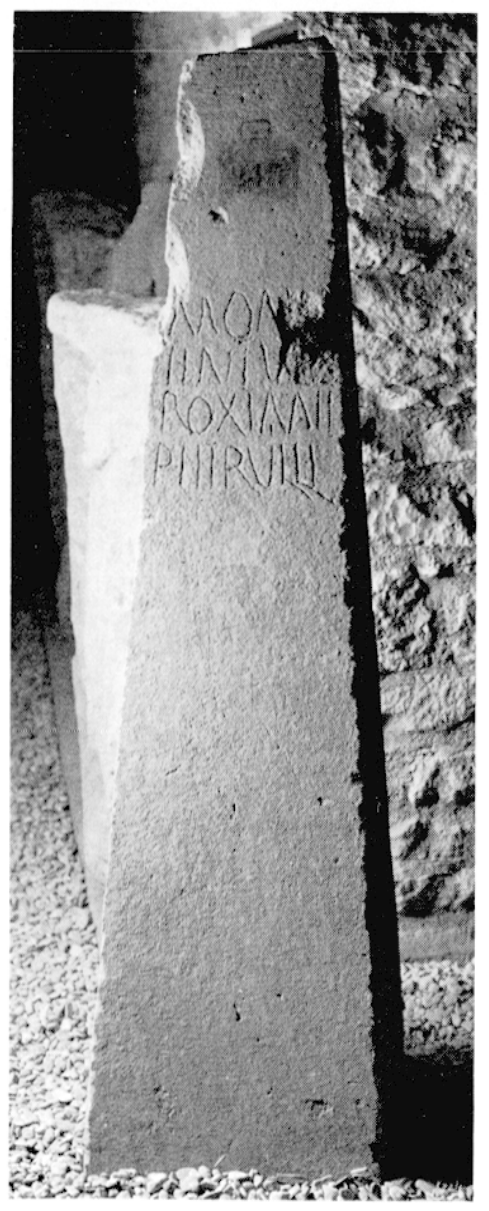


Petrullus : nom d'un potier ayant travaillé à Blickweiler et Eschweiler Hof (Sarre, RFA) à l'époque de Trajan et d'Antonin (Oswald, 1931, p. 413). Ce pourrait être un nom gaulois (sur la racine Petru-, voir Dottin, 1920, p. 278; sur la forme -ullus, $-a$, ibid., p. 108); mais Kajanto le considère comme un cognomen latin (Kajanto, 1965, p. 113).

Musée archéologique de Dijon, inv. 231.

Mém. CACO, 12, 1889-1895, p. xxvir-XxviI

(Joliet) - Catal. Musée CACO, $\mathrm{n}^{\circ} 231$ CIL XIII, 5557.

14 Découvert dans la propriété Nicolas; date, circonstances et contexte identiques à ceux du $\mathrm{n}^{\circ} 1$.

Fragment de pyramidion. Surface très usée. Pierre calcaire. Hauteur conservée : 20; largeur maximale conservée : 21,5 ; épaisseur maximale conservée : 18.

Inscription dont trois lignes sont conservées. Écriture médiocre. Gravure très usée, en particulier à la troisième ligne. Hauteur des lettres : 3 à $3,5 \mathrm{~cm}$.

\section{[d]M / MONIM / ENTVM / [...] $D$ (is) M(anibus) Monimentum ...}

l. 3 : E formé de deux barres verticales dont il ne reste plus que la partie supérieure. Les lettres $\mathrm{T}$ et $\mathrm{V}$ sont liées mais parfaitement lisibles, en dépit de la forme incurvée de la première branche du V. La lecture nrim, proposée par Lejay, est dépourvue de sens. Contrairement à l'affirmation de Mowat, le T est normalement formé.

Musée archéologique de Dijon, inv. 238.

Lejay, $1889, \mathrm{n}^{0} 172$ - Mowat, 1890, p. 417, $\mathrm{n}^{\circ} 30-$ Catal. Musée CACO, $\mathrm{n}^{\circ} 238-$ CIL XIII, 5585.

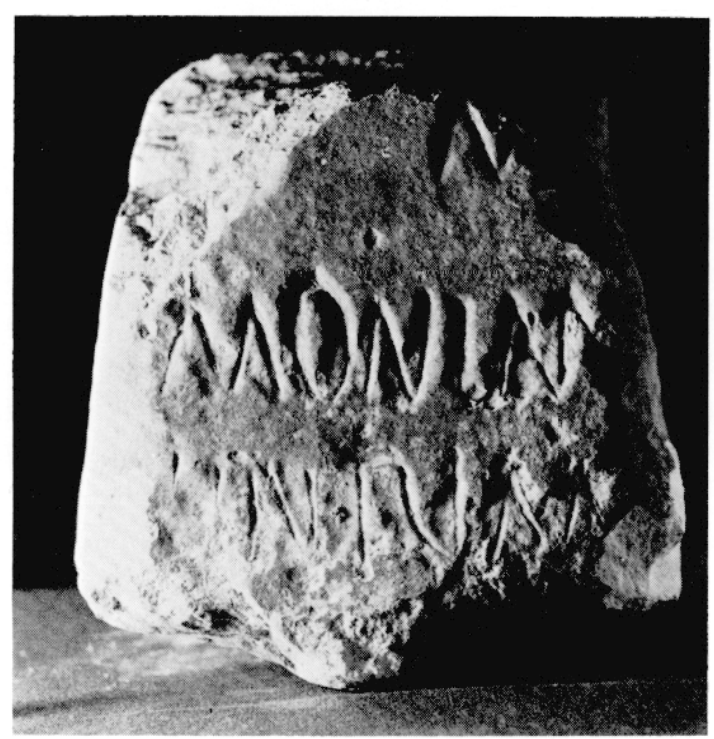

15 Découvert à l'emplacement du Collège des Godrans, actuellement entre la rue de l'École-deDroit et la rue du Petit-Potet, sans doute vers 15811585 , au moment de la construction du collège, en remploi dans le mur d'une tour du castrum.

Partie supérieure d'un pyramidion. Nature de la pierre et dimensions inconnues.

Inscription dont cinq lignes étaient conservées.

D . M / MON. FLAVINI / NANTIL. / ET / [...] D(is) M(anibus) Mon(umentum) Flavini Nantil(i) et ...

L'ensemble du texte, donné par Guénebauld, est incertain.

Flavinus : cognomen latin courant (Kajanto, 1965, p. 36, 161 et 227), connu en Gaule à Bordeaux (Gironde) (CIL XIII, 796), Worms (Rhénanie-Palatinat, RFA) (CIL XIII, 6232) et Nimègue (Gueldre, Pays-Bas) (CIL XIII, 8732); c'est aussi le nom de deux potiers, l'un de Gaule du Sud au r'r s., l'autre de Rheïnzabern (Rhénanie-Palatinat, RFA) à l'époque antonine (Oswald, 1931, p. 124).

Nantil ... : on connaît Nantius sur deux inscriptions de Bordeaux (Gironde) (CIL XIII, 666 et 805) et surtout Nantiorix à Dijon (CIL XIII, 5485). Sur Nanto-, Nantu-, voir Dottin, 1920, p. 274 et Evans, 1967, p. 236-237.

Perdu.

Guénebauld, 1621, p. 38 - Lejay, 1889, nº 91 CIL XIII, 5514 - Whatmough, 1970, p. 237.

16 Découvert à Dijon, avant 1771, dans des circonstances inconnues, sans doute en remploi dans le mur du castrum.

Pyramidion à base arrondie. Un éclat le long de l'arête droite de la face principale : il ne parait pas avoir endommagé l'inscription. Nature de la pierre inconnue. Hauteur: $\pm 140,4$; largeur maximale : $\pm 71,8$.

Inscription sur six lignes. L'écriture paraît régulière.

\section{S M. (?) / MNTM / PAVLIANI / PAVLI FILIVS. / ANNICENS. (?) / A C D. (?). \\ $<D>$ (is) M(anibus) (?) M(o)n(umen)t(u)m Pauliani \\ Pauli filius, Annicens...}

I. 1 : lecture erronée pour $D . M$. ? La restitution très compliquée proposée par Lejay - [D(is) M(anibus)] $S($ acrum $) M(o)[n(u)] m(e) n l(u) m$ - se justifie d'autant moins que la formule D.M.S. serait exceptionnelle dans la région; 
1. 2 : dans son texte, Legouz donne MNMT au lieu de MNTM sur le dessin. Il faudrait alors restituer $M(o) n(u) m(e n) t(u m)$;

1. $3: \operatorname{deux} \mathrm{A}$ à barre tombante;

1. 4 : A à barre tombante. Le $\mathrm{F}$ paraît ne comporter qu'une barre horizontale. On devrait avoir filii;

1. 5 et 6 : la restitution Annicensa c(oniugi) d(at) proposée par le CIL suppose l'utilisation d'une formule rare et une coupure du nom propre d'autant plus étrange qu'il restait assez de place pour le A à la fin de la ligne 5 et que cette ligne paraît se terminer par un point. Cette lecture est donc peu satisfaisante. Lejay supposait que la copie de Legouz était mauvaise et proposait de restituer une formule du type Annicen(u)s p(onendum) c(uravit). Elle paraît assez plausible, en dépit de la rareté des formules de curatelle sur les monuments funéraires dijonnais.

Paulianus, Paulus : cognomina latins (Kajanto, 1965, p. 243-244). On connaît un Paulus Pauliani filius à Saintes (Charente-Maritime) (CIL XIII, 1089), un Paullianus à Étaules (Côte-d'Or) (CIL XIII, 5620). Paulus est mentionné huit autres fois dans le tome XIII du CIL, dont trois fois pour des épitaphes chrétiennes.

Annicen ... : ce nom ne paraît pas connu ailleurs. La forme la plus proche connue en Gaule serait Anicetus, - $a$ (six mentions dans le tome XIII du $C I L)$. On peut penser également aux cognomina latins Anneianus, Annianus (Kajanto, 1965, p. 140).

Perdu.

Legouz de Gerland, 1771, p. 125 et pl. XVIII, $\mathrm{n}^{\circ} 1$ - Lejay, $1889, \mathrm{n}^{\circ} 109-$ CIL XIII, 5548.

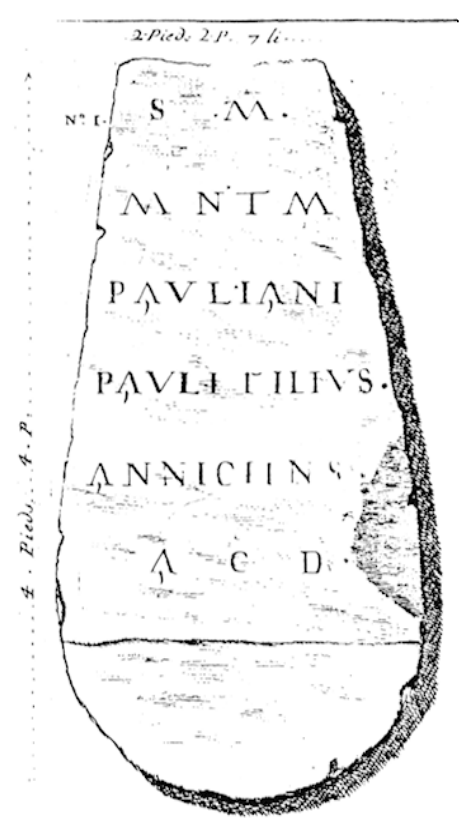

Dessin extrait de Legouz de Gerland, 1771, pl. XVIII, no 1.
17 Découvert au lieu-dit Les Poussots. Date, circonstances et contexte inconnus.

Partie supérieure d'un pyramidion soigneusement taillée mais assez érodée.

Pierre calcaire. Hauteur conservée : 31 ; largeur maximale conservée : 18; largeur au sommet : 14; épaisseur maximale conservée : 16 ; épaisseur au sommet : 10.

Inscription dont trois lignes sont conservées. Écriture régulière de bonne qualité. Gravure profonde. Hauteur des lettres : 5,5 à $6 \mathrm{~cm}$.

$$
\begin{gathered}
\text { D / MON / MEN / [tum] / ... } \\
\text { D(is Manibus) (?) Mon(u)mentum ... }
\end{gathered}
$$

1. 1 : le M qui devrait suivre le D n'a pas été gravé; 1. 3 : ligature du $M$ et du $E$. La fin du mot était probablement gravée sur la quatrième ligne.

Musée des Antiquités nationales de Saint-Germain-en-Laye, inv. 50491.

Desjardins, 1880 , p. 137 - Lejay, $1889, \mathrm{n}^{\circ} 129$

- Mowat, 1890 , p. $422, \mathrm{n}^{\circ} 42-C I L$ XIII, 5490 - Reinach, 1917, p. 229, nº 50491.

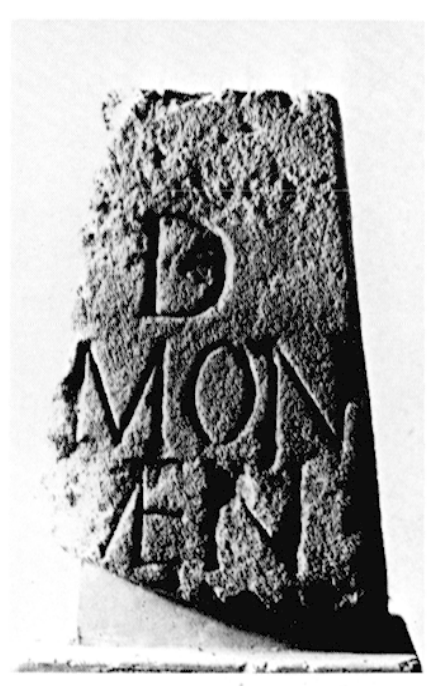

18 Découvert à Dijon? Le CIL paraît considérer que ce pyramidion fait partie des "monuments tumulaires" vus par Rossignol, vers 1846, "dans les sablières du grand cours Fleury, cours Ignace, allée de la Retraite" et "sur lesquels, au lieu de $D$. $M$., se trouve $M . D . »$. Outre la contradiction contenue dans l'indication de provenance (voir $n^{\circ} 8$ ), on constate que cette inscription n'est pas précisément citée par Rossignol dans le compte rendu des Mém. CACO. Date et circonstances inconnues.

Partie supérieure d'un pyramidion. Important éclat sur l'arête gauche de la face principale. Nature de la pierre inconnue. Hauteur conservée : 38. 
Inscription dont trois lignes sont conservées. L'écriture paraît d'assez bonne qualité.

\section{D / MO <n $>$ [i] (?) / MIN / [tum] (?) / [...] $M$ (anibus) $D$ (is) (?) Monimintum... (?)}

l. 2 : le A copié par Caumont est peu vraisemblable, alors qu'un $\mathrm{N}$ permet de donner un sens à l'ensemble des lignes 2 et 3.

Caumont et le $C I L$ indiquent que ce monument est conservé au Musée archéologique de Dijon mais nous ne l'y avons pas retrouvé et il n'est pas signalé dans le catalogue du musée de 1894. Est-ce le fragment ci-dessous, non inventorié? Il aurait été recassé à la partie inférieure.

Caumont, 1870, p. 521 - CIL XIII, 5544.

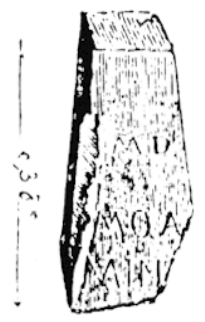

Dessin extrait de Caumont, 1870 , p. 521.

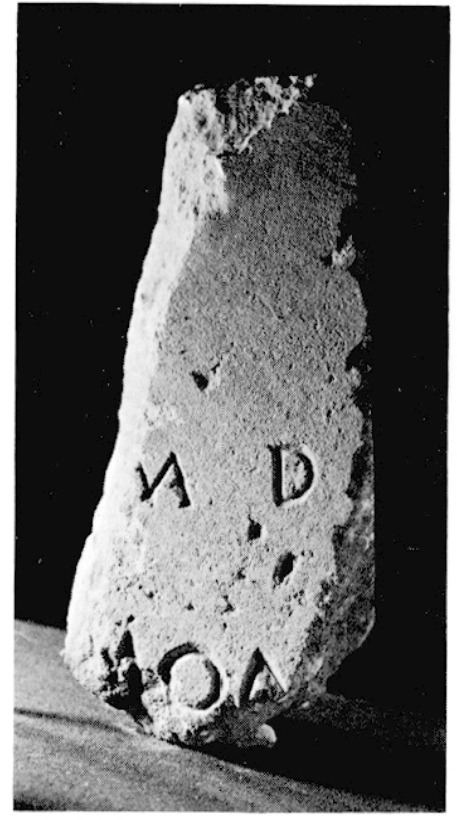

HOC / MO[n] / MEN / [i]VLIAE / SOLLE / MNIS Sur le côté droit, à la hauteur de la troisième ligne :

$[\mathrm{t}] \mathrm{VM}$

Hoc mon(u)mentum Iuliae Sollemnis.

l. 3 : E formé de deux barres verticales;

1. 4 : I initial à la limite de la cassure. L à barre oblique. La barre horizontale du A a été omise. $E$ formé de deux barres verticales;

1. 5 : deux L à barre oblique. E formé de deux barres verticales.

Côté droit - Cette syllabe se lit à la suite de la ligne 3 .

Iulia: gentilice bien attesté en Gaule. On retiendra particulièrement les inscriptions de SainteSabine (Côte-d'Or) (CIL XIII, 2835), Essarois (Côted'Or) (CIL XIII, 5646) et Langres (Haute-Marne) (CIL XIII, 5785).

Sollemnis: cognomen latin (Kajanto, 1965, p. 221) mentionné seize fois dans le tome XIII du $C I L$. On le trouve dans diverses régions de Gaule, en particulier à Alise-Sainte-Reine (Côte-d'Or) (Wuilleumier, 1963, $\mathrm{n}^{\circ} 327$ ) et en Germanie.

Musée archéologique de Dijon, inv. 228.

Lejay, $1889, \mathrm{n}^{\circ} 170$ - Catal. Musée CACO, $\mathrm{n}^{\circ} 228-$ CIL XIII, 5523.
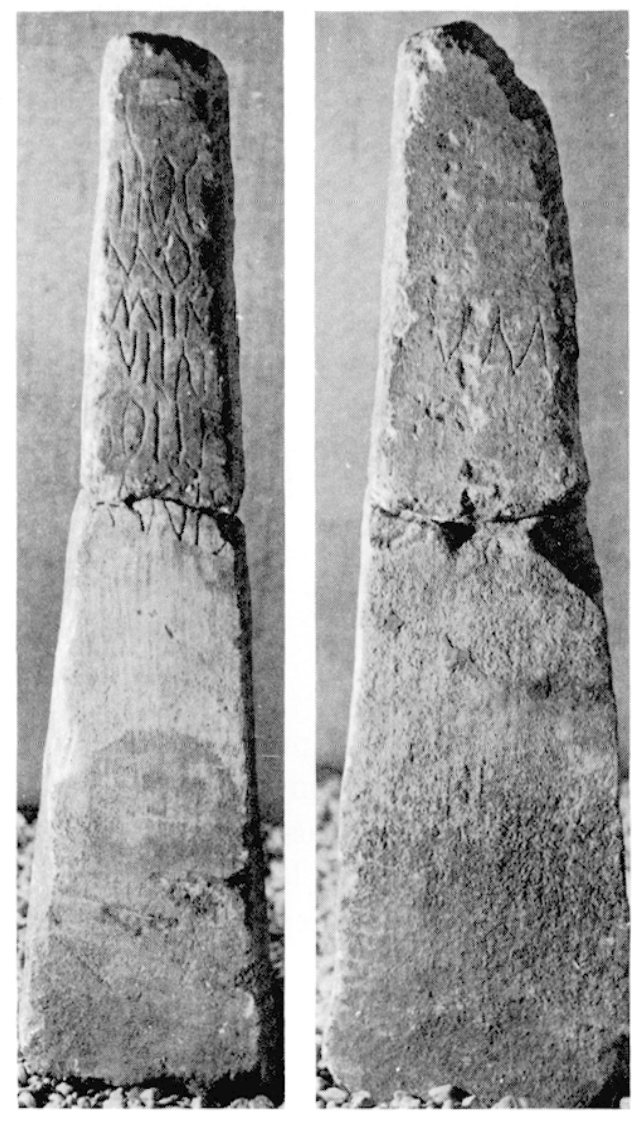

A gauche, face principale; $\dot{a}$ droite, face
latérale.

A gauche, face principale; $\dot{a}$ droite, face
latérale.
19 Découvert au lieu-dit Les Lentillières, dans la sablière de $M$. Buet (section $P$, parcelles $97-98$ de l'ancien cadastre), acluellement entre le chemin des Lentillières, le boulevard Robert-Schumann et la rue du Chanoine-Denizot; en 1868, dans des circonstances inconnues.

Pyramidion en deux fragments, assez grossièrement taillé. Pierre calcaire. Hauteur : 67 ; largeur à la base : 16 ; largeur au sommet : 7,5 ; épaisseur à la base : 20 ; épaisseur au sommet : 9 .

Inscription sur six lignes. Ecriture irrégulière et de mauvaise qualité. Gravure étroite et peu profonde. Hauteur des lettres : 2,4 à 4,8 cm. 
20 Découvert à l'emplacement du Collège des Godrans, actuellement entre la rue de l'École-deDroit et la rue du Petit-Potet, sans doute vers 15811585 , au moment de la construction du collège, en remploi dans le mur d'une tour du castrum.

Nature de la pierre et dimensions inconnues. Inscription sur trois ou quatre lignes.

Richard : MONVMENTVM / IVNIANI / OX... Guénebauld : MOMNIIVS / IAXIV / OVXXRII / AISC...

Monumentum Iuniani $0 x \ldots$

Seule la transcription de Richard permet de donner un sens à l'inscription, mais la troisième ligne est certainement en partie inexacte.

Iunianus : cognomen latin (Kajanto, 1965, p. 32 et 148) courant dans toute la Gaule (quinze mentions dans le tome XIII du CIL). On notera particulièrement sa présence sur un autre pyramidion de Dijon $\left(\mathrm{n}^{\circ} 30\right)$.

$O x \ldots$ : les deux premières lettres relevées par Richard sont vraisemblables. On trouve en effet Oxia à Besançon (Doubs) (CIL XIII, 5370), Oxtaia à Luxeuil (Haute-Saône) (CIL XIII, 5441), Oxtaius à Mandeure (Doubs) (CIL XIII, 5408) et à AliseSainte-Reine (Côte-d'Or) (CIL XIII, 11240), Ox/t]antia (?) sur le calendrier de Coligny (Ain) (Duval, Pinault, 1986, p. 425), etc.

Perdu.

Richard, 1585, folio 42 - Guénebauld, 1621, p. 37 - Lejay, 1889, no $89-C I L$ XIII, 5525.

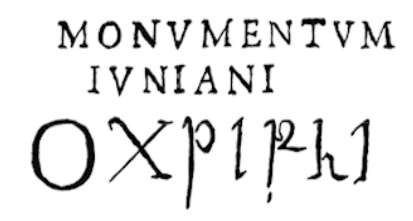

D'après Richard, 1585, folio 42.

21 Découvert dans la propriété Nicolas; date, circonstances et contexte identiques à ceux du $n^{\circ} 1$.

Pyramidion assez grossièrement taillé. Pierre calcaire. Hauteur : 109; largeur à la base : 30 ; largeur au sommet : 14; épaisseur à la base : 26 ; épaisseur au sommet : 14,5.

Inscription sur six lignes. Écriture médiocre mais lettres assez régulières. Gravure étroite mais profonde. Un trait horizontal gravé à la base de chaque ligne a servi de guide. Hauteur des lettres: 4,7 à $5 \mathrm{~cm}$.

\section{MONI / MINTO / CACVD / IASVA / DVGENI / CENI (?). \\ Moniminto Cacudia Suadugeni (filia?).}

1. 1 et $2:$ Moniminto pour monumentum;

I. 5: le $\mathrm{G}$ comporte une longue barre oblique.

$E$ formé de deux barres verticales;

1. 6: E formé de deux barres verticales. Cette dernière ligne paraît reprendre, légèrement modifiée, la fin de la ligne 5 .

Cacudia : ce nom ne paraît pas connu ailleurs en Gaule. A rapprocher de Cacusi filia à Lamargelle (Côte-d'Or) (Wuilleumier, 1963, $\mathrm{n}^{\circ}$ 411).

Suadugenus : on connaît Suadugenu filia à Autun (Saône-et-Loire) (CIL XIII, 2751) et Suadugena à Périgueux (Dordogne) (CIL XIII, 11050). Dottin le considère comme un nom gaulois (Dottin, 1920, p. 108). Le nom Dugenus n'étant pas attesté, la lecture Cacudia Suadugeni est la plus vraisemblable.

Musée archéologique de Dijon, inv. 227.

Lejay, $1889, \mathrm{n}^{\circ} 137$ - Mowat, 1890 , p. 417, $\mathrm{n}^{0} 31$ - Calal. Musée CACO, $\mathrm{n}^{\circ} 227$ - CIL XIII, 5502 - Evans, 1967, p. 113 et 319-320 - Whatmough, 1970, note (LII) (a), p. 988-989.

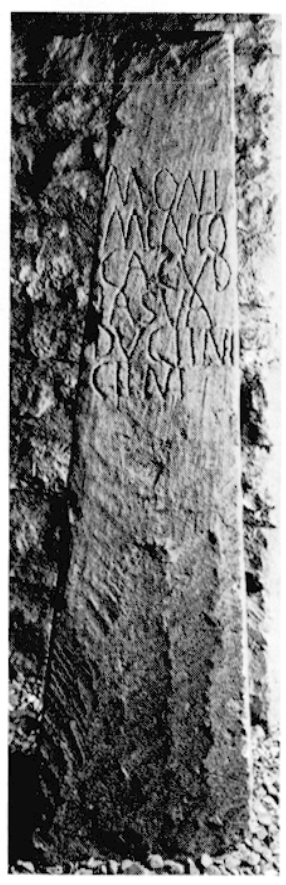

22 Découvert au lieu-dit Les Poussots. Date, circonstances et contexte inconnus.

Fragment d'un pyramidion, assez soigneusement taillé. Pierre calcaire. Hauteur conservée : 14,5; largeur maximale conservée : 19,5; épaisseur maximale conservée : 14. 
Inscription dont trois lignes sont partiellement conservées. Lettres régulières comportant de nombreuses particularités. Gravure large et profonde. Hauteur des lettres : 3 à $3,5 \mathrm{~cm}$.

\section{$[\mathrm{m}] \mathrm{ONIM} /[\mathrm{en}] \mathrm{TVM} /[\ldots] \mathrm{MER} /[\ldots]$ Monimentum ...mer...}

1. 1 : on distingue au bord de la cassure l'extrémité de la dernière barre du premier M. La partie inférieure de la première barre du $\mathrm{N}$ est courbe. Les barres extrêmes $d u$ dernier $M$ sont légèrement convexes et terminées, de même que le I, par une petite barre horizontale;

1. 2 : la trace du $\mathrm{N}$ est visible au bord de la cassure. Le $\mathrm{T}$ est muni d'une barre horizontale supplémentaire au pied. La première barre du $\mathrm{V}$ est courbe. $\mathrm{M}$ identique à celui de la ligne 1 , à l'exception de la dernière barre dont la courbure est inversée;

1. 3 : il manque sans doute au moins deux letlres au début de la ligne. La restitution [S/mer/tullus], proposée par Lejay, ne paraît donc pas justifiée. La boucle du R n'est pas fermée. Il est très probable qu'il existait au moins une quatrième ligne.

Musée archéologique de Dijon, inv. 242.

Lejay, 1889, no 124 - Catal. Musée CACO, n” $242-$ CIL XIII, 5579.

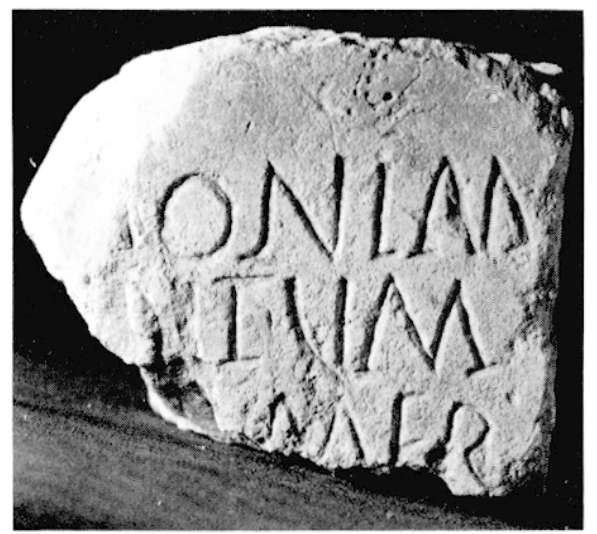

23 Découvert dans la propriété Nicolas. Date, circonstances et contexte identiques à ceux du $\mathrm{n}^{n} 1$.

Partie supérieure d'un pyramidion. Surface extrêmement usée. Pierre calcaire. Hauteur conservée : 44 ; largeur maximale conservée : 27 ; largeur au sommet : 25 ; épaisseur maximale conservée : 14 ; épaisseur au sommet : 12 .

Inscription dont trois lignes sont partiellement conservées. La partie droite de chaque ligne a été complètement effacée par l'usure. L'écriture paraît régulière et de qualité moyenne. Hauteur des lettres : 4,2 à $4,7 \mathrm{~cm}$.

\section{$\mathrm{MO}[\mathrm{nim}] / \mathrm{ENT}[\mathrm{um}] / \mathrm{TO}[\ldots]$ \\ Monimenlum To...}

l. 3: la troisième lettre peut être un I ou, plus probablement, une autre lettre commençant par une barre verticale. Cette ligne est sans doute le début du nom du défunt.

Musée archéologique de Dijon, inv. 237.

Lejay, $1889, \mathrm{n}^{\circ} 175$ - Catal. Musée CACO, $\mathrm{n}^{\mathrm{o}} 237-$ CIL XIII, 5584.

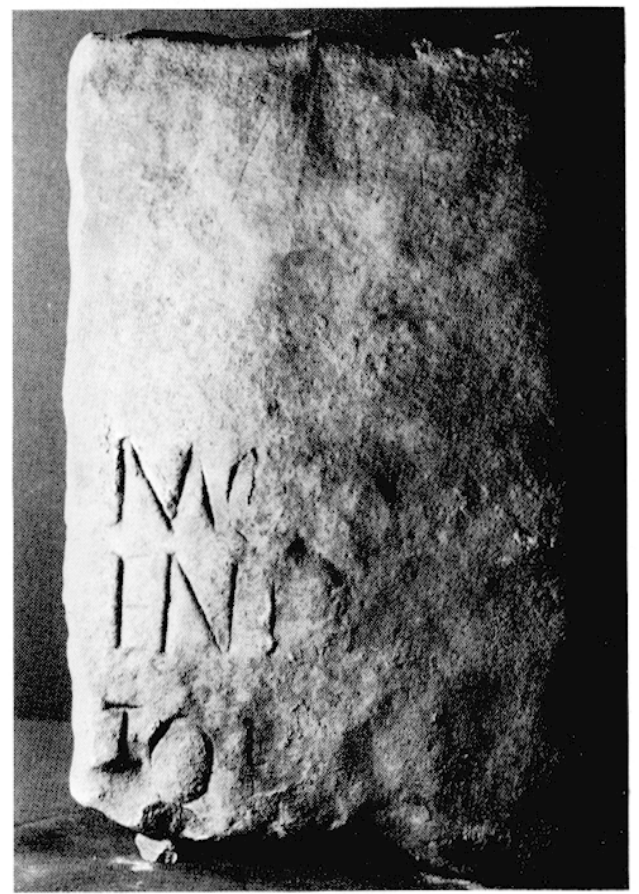

24 Découvert dans le lit du Suzon, vers l'ancien jardin botanique, actuellement entre la rue MauriceChaume et la rue de Mirande, à l'ouest du boulevard Voltaire; en 1830, dans des circonstances fortuites, avec un fragment de stèle et les pyramidions $n^{\text {os }} 26$ et 31 .

Partie supérieure d'un pyramidion assez grossièrement taillée et très usée. Pierre calcaire. Hauteur conservée : 40 ; largeur maximale conservée : 21 ; largcur au sommet : 17 ; épaisseur maximale conservée : 20 ; épaisseur au sommet : 15.

Inscription sur quatre lignes. Écriture de mauvaise qualité. Gravure assez profonde pour les deux premières lignes, beaucoup plus superficielle pour les deux dernières. Hauteur des lettres : $4 \mathrm{~cm}$.

\section{TVM / MONIME[n] / [...]VMI[...] / [...]VM Monimentum ...}

1. 1 : cette syllabe complète la ligne 2 pour former le mot monimentum; 
1. 2: E formé de deux barres verticales;

1. 3 et 4 : ces deux lignes difficiles à lire forment-elles le nom du défunt ou sont-elles la reprise maladroite des lignes 1 et 2 ?

Musée archéologique de Dijon, inv. 235.

Mém. Acad. Dijon, 1831, p. 40-41 - Lejay, $1889, \mathrm{n}^{\circ} 142$ - Mowat, 1890 , p. $416, \mathrm{n}^{\circ} 29-$ Calal. Musée CACO, n $235-C I L$ XIII, 5545.

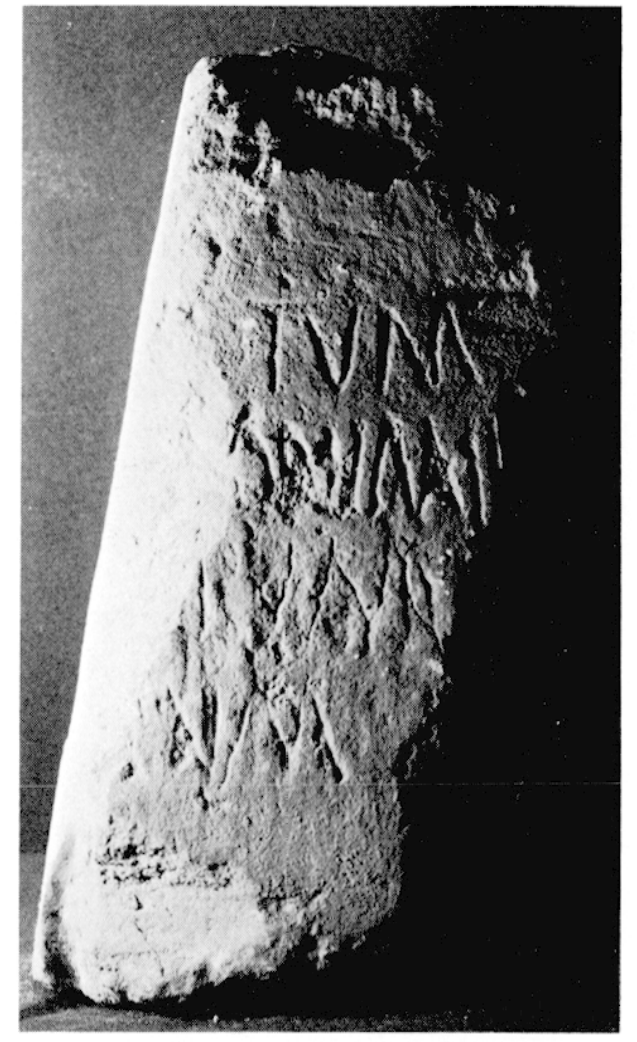

25 Découvert au lieu-dit Les Poussots. Date, circonstances et contexte inconnus. Pyramidion comportant de nombreuses traces de scie sur les faces latérales et postérieure. Pierre calcaire. Hauteur : 44 ; largeur à la base : 13,5; largeur au sommet : 11,5 ; épaisseur à la base : 15,5 ; épaisseur au sommet: 12 .

Inscription sur trois lignes. Écriture irrégulière. Gravure profonde. Hauteur des lettres : 3,5 à 7,5 cm.

\section{MO / NIMI / TILLICI Monimi(ntum) Tillici.}

1. 2 : la hauteur du $M$ est nettement inférieure à celle des autres lettres;

1. 3 : la barre horizontale du T est recourbée vers le haut. Les barres horizontales des deux L sont très longues, recourbées vers le haut et détachées de la barre verticale.
Tillicus: ce nom se retrouve, également au génitif mais avec un seul $\mathrm{L}$, sur une stèle funéraire de Langres (Haute-Marne) (CIL XIII, 5696).

Musée des Antiquités nationales de Saint-Germain-en-Laye, inv. 50490.

Desjardins, 1880 , p. 138 - Lejay, 1889, $n^{\circ} 131$

- Mowat, 1890, p. 422, $\mathrm{n}^{\circ} 41$ - CIL XIII 5575

- Reinach, 1917, p. 229, no 50490.

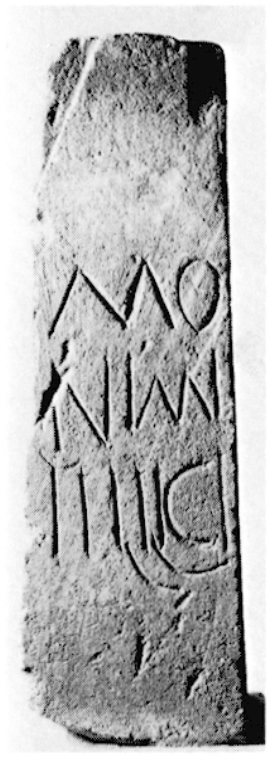

26 Découvert dans le lit du Suzon, vers l'ancien jardin botanique. Date, circonstances et contexte identiques à ceux du $\mathrm{n}^{\circ} 24$.

Pyramidion assez soigneusement taillé. Un gros éclat en haut à droite de la face principale a entamé la première ligne de l'inscription. Pierre calcaire. Hauteur : 89 ; largeur à la base : 34 ; largeur au sommet : 16 ; épaisseur à la base : 21 ; épaisseur au sommet : 16 .

Inscription sur trois lignes. Écriture de qualité moyenne. La gravure, usée, devait ètre assez profonde. Un trait horizontal gravé à la base de chaque ligne a servi de guide. Hauteur des lettres: 2 à. $2,4 \mathrm{~cm}$.

\section{MON[im] / LEPIDI / LIPPONIS Monim(entum) Lepidi Lipponis.}

I. 1 : l'amorce de la dernière lettre, au bord de la cassure, est trop oblique pour être un I. Il s'agit plutôt d'un M. Le I pouvait former une ligature avec le $\mathrm{N}$ ou le $\mathrm{M}$ ou bien avait été omis;

I. 2: E formé de deux barres verticales;

I. 3 : le $\mathrm{L}$ initial est beaucoup plus grand que les autres lettres. 
Lepidus : cognomen latin (Kajanto, 1965, p. 283) courant dans toutes les régions de Gaule (quatorze mentions dans le tome XIII du CIL). C'est aussi le nom d'un potier de Gaule du Sud de l'époque TibèreNéron (Oswald, 1931, p. 161) et d'un potier de Rheinzabern (Rhénanie-Palatinat, RFA) de l'époque d'Antonin (Oswald, 1931, p. 161).

Lippo: ce cognomen latin (Kajanto, 1965, p. 118-119 et p. 239) n'est pas mentionné dans le tome XIII du CIL, mais c'est le nom d'un potier de Trèves (Rhénanie-Palatinat, RFA) de l'époque d'Antonin (Oswald, 1931, p. 165).

Musée archéologique de Dijon, inv. 233.

Mém. Acad. Dijon, 1831, p. 40-41 - Rossignol, 1854 , p. 569 - Caumont, 1870, p. 521 - Lejay, $1889, \mathrm{n}^{\circ} 140$ - Calal. Musée CACO, no 233 CIL XIII, 5528 .

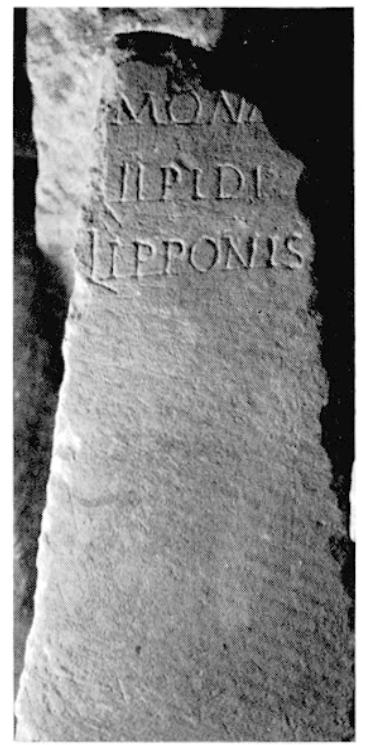

27 Découvert route de Mirande, près de l'ancien bureau d'octroi, actuellement rue de Mirande, entre la rue J.-B. Baudin et le boulevard Voltaire; en 1890 , en creusant une tranchée d'égout.

Pyramidion assez soigneusement taillé mais érodé. Pierre calcaire. Hauteur : 69; largeur à la base : 29 ; largeur au sommet: 18 ; épaisseur à la base : 22 ; épaisseur au sommet : 13,5 .

Inscription sur quatre lignes. Ecriture de très mauvaise qualité. Gravure profonde. Hauteur des lettres : 2,5 à $6 \mathrm{~cm}$.

\section{MONIM / SATRIO / SEVERINI / FILIVS} Monim(entum) Satrio Severini filius.
1. 1 : la troisième barre du premier $M$ manque. Les deux dernières barres du deuxième $M$ n'ont pas été gravées faute de place;

1. 2: la barre transversale du A a été omise. Les troisième et quatrième lettres sont incertaines, mais $\mathrm{T}$ et $\mathrm{R}$ paraissent vraisemblables;

1. 3 : les trois dernières lettres sont très serrées par manque de place;

1. $4: \mathrm{F}$ formé de deux barres verticales inégales. $\mathrm{L}$ à barre oblique. Les deux branches du $\mathrm{V}$ ne sont pas jointives. La partie supérieure du $\mathrm{S}$ se prolonge jusqu'à l'angle de la pierre.

Satrio: ce cognomen latin (Kajanto, 1965, p. 165) ne paraît pas connu ailleurs en Gaule mais se trouve sur une inscription de Salone (Croatie, Yougoslavie) (CIL III, 8921). Peut-être faut-il le rapprocher de Saturio, nom connu sur le limes au nord de Francfort (Hesse, RFA) (CIL XIII, 7442 et 7494), à Mayence (Rhénanie-Palatinat, RFA) (CIL XIII, 6684) et à Bordeaux (Gironde) (CIL XIII, 762) et qui est aussi le nom d'un potier de Rheinzabern (Rhénanie-Palatinat, RFA) de l'époque d'Hadrien et d'Antonin (Oswald, 1931, p. 282).

Severinus: cognomen latin (Kajanto, 1965, p. 257) très répandu en Gaule; on le trouve en particulier trois fois à Lyon (Rhône) (CIL XIII, 1695, 1894 et 1964). Il est aussi courant en Germanie.

Musée archéologique de Dijon, inv. 1886.

Catal. Musée CACO, no 1886 - CIL XIII, 5566 et XIII, IV, p. 73.

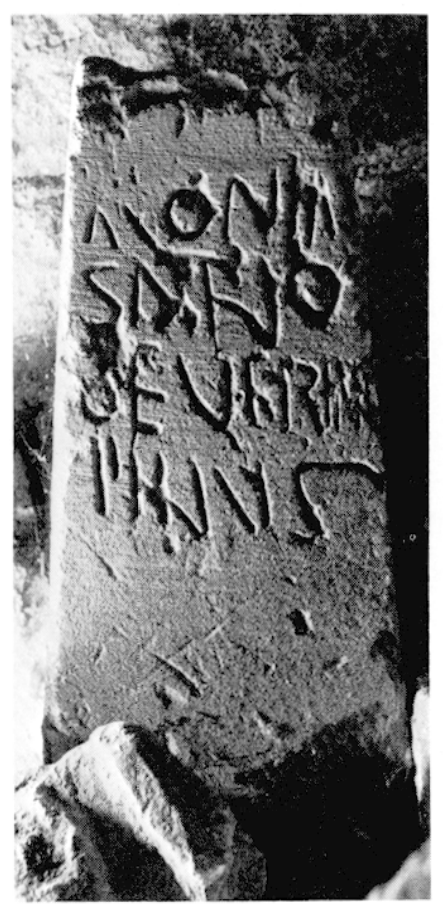


28 Découvert au lieu-dit Les Poussots, probablement en $1866^{22}$, dans des circonstances inconnues. Le même compte rendu de découverte mentionne une sépulture par incinération, pour laquelle une monnaie d'Hadrien fournit un terminus post quem, et une pierre carrée sur laquelle étaient gravés un compas et une équerre et qui provenait sans doute d'un autre monument funéraire. Mais il n'est pas possible d'établir de relation précise entre ces trois éléments.

Partie supérieure d'un pyramidion en "pierre d'Asnières" (Lépine). Hauteur conservée : 17,5; largeur maximale conservée : 16,5 ; largeur au sommet : $11^{23}$.

Inscription dont trois lignes et la partie supérieure d'une quatrième sont conservées. Écriture médiocre. Hauteur des lettres : 3,2 à $4 \mathrm{~cm}$.

\section{MO. / MAX / MINIA / mo[.]vi (?) Mo(numentum) Maxminia Moui.}

1. 1 : un point rond est gravé au centre du 0 ;

1. 4 : la ligne paraît commencer à nouveau par un $\mathrm{M}$. La deuxième lettre peut être un 0 ; la troisième un $\mathrm{C}$, un $\mathrm{G}$ ou un $\mathrm{S}$. Pour terminer, probablement $\mathrm{V}$ et I. Il n'est absolument pas possible de restituer la syllabe $\mathrm{TA}$ entre la troisième et la quatrième lettre, comme le proposait le $C I L$, qui ne connaissait l'inscription que par le compte rendu des Mém. CACO. Il est difficile de savoir si le nom gravé sur cette ligne est complet.

Maxminia: Maximinia est un cognomen latin (Kajanto, 1965, p. 276), mais n'est pas attesté en Gaule sous cette forme. On connaît Maximina sur quatre inscriptions de Germanie (CIL XIII, 6678, 7077, 7352 bis et 8290) et le masculin Maximinus sur deux ou trois inscriptions de Germanie (CIL XIII, 7352 bis, 11697 et peut-être 6639) et une de Lyon (Rhône) (CIL XIII, 2140). La variante Maxminus, avec suppression du I entre le $\mathrm{X}$ et le $\mathrm{M}$ se trouve à Arlon (Luxembourg, Belgique) (CIL XIII, 3983), Kälbertshausen (Bade-Wurtemberg, RFA) (CIL XIII, 6486) et Saverne (Bas-Rhin) (CIL XIII, 11660). On peut rapprocher cette particularité de celle observée par M. Lejeune sur les variantes Decm- pour Decim- dans le Nord-Est de la Gaule (Lejeune, 1982, p. 150).

Mocuus, Moguus, Mosuus : aucun de ces noms

22 Le compte rendu des Mém. CACO date la découverte de 1856. Le dessin de Lépine porte la date de 1866, ce qui parait plus vraisemblable puisque la découverte est signalée dans le compte rendu des travaux de 1866-1867.

23 Le dessin de Lépine à partir duquel cette notice a èté établie a été exécuté d'après un estampage également conservé dans les archives de la $C A C O$. Il est donc grandeur réelle. ne paraît connu en Gaule. On peut cependant en rapprocher Moccus, surnom de Mercure sur une inscription de Langres (Haute-Marne) (CIL XIII, 5876). On connaît également Mocus et Mocius dans la région des Champs Décumates (Whatmough, 1970, p. 1288-1289).

Perdu.

Lépine, 1866 - Mém. CACO, 7, 1865-1869, p. LXXII (Lépine) - Lejay, $1889, \mathrm{n}^{\circ} 134-C I L$ XIII, 5541.

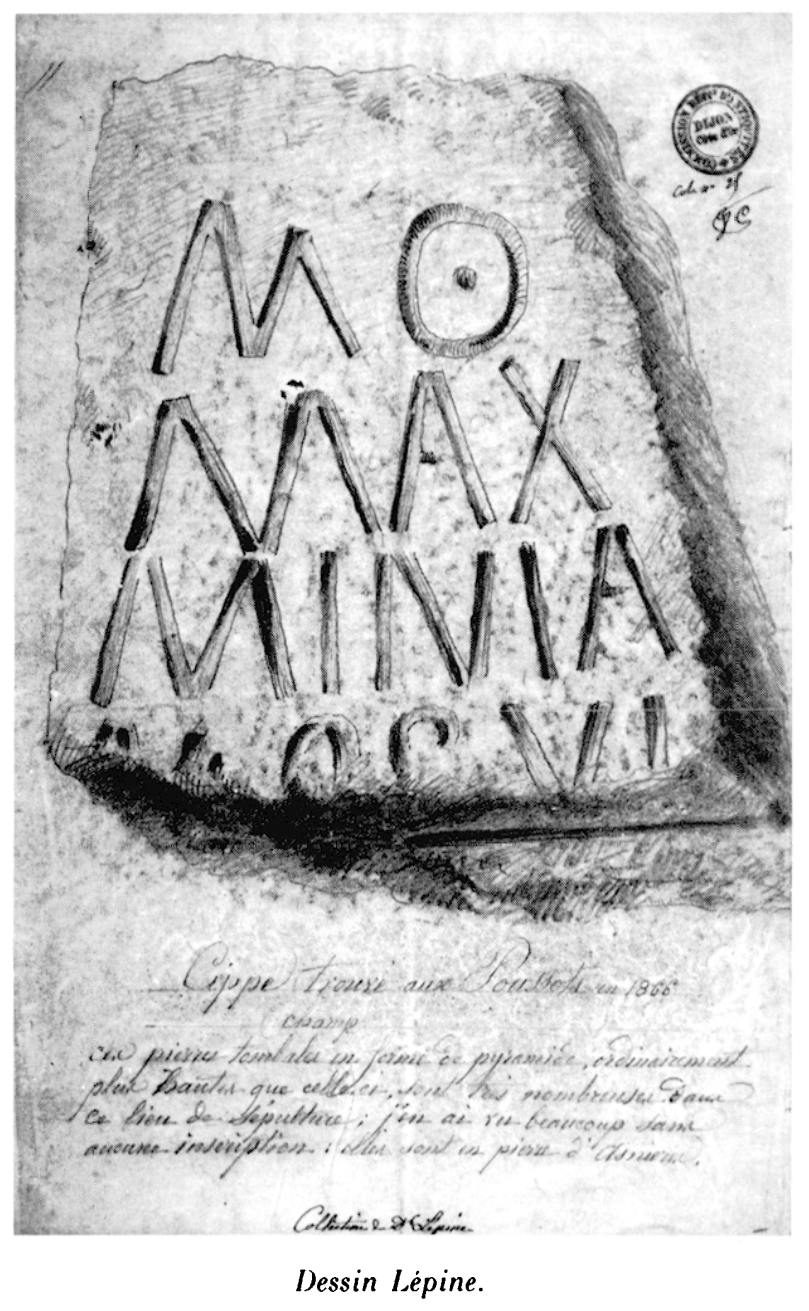

29 Découvert au lieu-dit Les Poussots. Date, circonstances et contexte inconnus.

Pyramidion soigneusement taillé. Traces de scie sur une des faces latérales. Pierre calcaire. Hauteur : 115 ; largeur à la base : 28,5; largeur au sommet : 11,5 ; épaisseur à la base: 26,5 ; épaisseur au sommet : 10.

Inscription sur quatre lignes. Écriture médiocre. Gravure profonde. Hauteur des lettres : 3,5 à $5 \mathrm{~cm}$.

$$
\begin{aligned}
& \text { M.LIT / VGE / NIBI / RACATI } \\
& \text { M(onumentum) Litugeni Biracati. }
\end{aligned}
$$


1. 1 : L à barre oblique;

1. 2: E formé de deux barres verticales;

1. 4 : deux A à barre tombante.

Litugenus: ce nom se retrouve à Chaufailles (Saône-et-Loire) (CIL XIII, 2581), à Grand (Vosges) (CIL XIII, 5950), à Vaison-la-Romaine (Vaucluse) (CIL XII, 1293) ainsi qu'à Rennes (Ille-et-Vilaine) et à Mauves (Loire-Atlantique) sur des fibules de la première moitié $\mathrm{du} \mathrm{I}^{\mathrm{er}} \mathrm{s}$., sans doute de fabrication locale (Galliou, 1984, p. 161). Le féminin Litugena est attesté à Paris (Seine) (CIL XIII, 11275) et Narbonne (Aude) (CIL XII, 5022). La racine Litu- est celtique (Evans, 1967, p. 217-218).

Biracalus : ce nom se trouvait également sur une stèle funéraire de Dijon trouvée en remploi dans le mur du castrum et aujourd'hui perdue (CIL XIII, $5522)^{24}$. C'est aussi le nom d'un potier de Gueugnon de l'époque antonine (Gaillard, Parriat, 1975, p. 327 et 369-373). Nom formé sur la racine celtique Birac(Evans, 1967, p. 311-313). On trouve également Birako- en caractères grecs, à Alise-Sainte-Reine (Côte-d'Or) (Evans, 1967, p. 313-314) et Biracus sur une stèle de Til-Châtel (Côte-d'Or) (Deyts, 1976, n" 204).

Musée des Antiquités nationales de SaintGermain-en-Laye, inv. 50488.

Desjardins, 1880 , p. 136 - Lejay, 1889, n 128

- Mowat, 1890 , p. 422 , n" $43-$ CIL XIII, 5529 - Reinach, 1917, p. 229, n*50488.

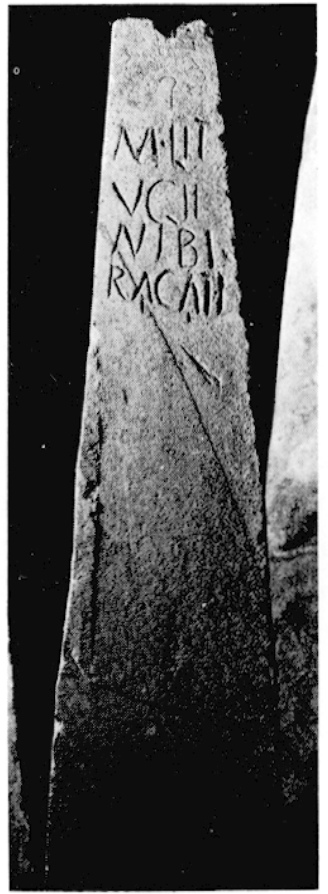

30 Découvert à Dijon, avant 1854 , dans des circonstances inconnues, peut-être en remploi dans le mur du castrum ${ }^{25}$.

Pyramidion assez soigneusement taillé. Pierre calcaire. Hauteur : 53 ; largeur à la base : 16,5; largeur au sommet : 13,5 ; épaisseur à la base : 14,5; épaisseur au sommet: 12 .

Inscription sur deux lignes. Écriture d'assez bonne qualité. Gravure profonde. Hauteur des lettres : 2,5 à $3,5 \mathrm{~cm}$.

\section{M / IVNIANI M(onumentum) Iuniani.}

1. 1 : il ne semble pas qu'il y ait eu une seconde lettre à l'emplacement de la cassure;

l. 2 : le deuxième I prolonge vers le haut la seconde barre verticale $\mathrm{du} \mathrm{N}$.

Iunianus : voir n" 20.

Musée archéologique de Dijon, inv. 245.

Rossignol, 1854, p. 569 - Caumont, 1870, p. 521 - Lejay, 1889, n 67 - Catal. Musée $C A C O, \mathrm{n}^{\circ} 245-C I L$ XIII, 5524.

25 Lejay (1889) et le $C I L$ donnent cette provenance sans autre précision et sans donner leur source.

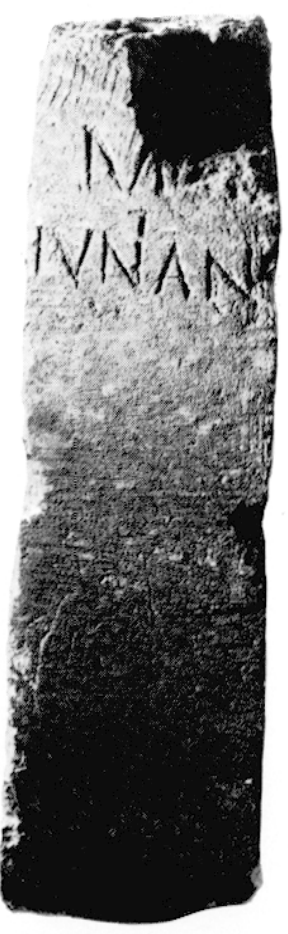

31 Découvert dans le lit du Suzon, vers l'ancien jardin botanique. Date, circonstances et contexte identiques à ceux du $\mathrm{n}^{\circ} 24$.

Pyramidion assez grossièrement taillé et érodé. Pierre calcaire. Hauteur : 80 ; largeur à la base : 27 ; 
largeur au sommet : 17 ; épaisseur à la base : 20 ; épaisseur au sommet : 10 .

Inscription sur deux lignes. Écriture médiocre. Gravure étroite mais assez profonde. Hauteur des lettres : 2,5 à $4,7 \mathrm{~cm}$.

\section{APPIAE / AVGVSTAE Appiae Augustae.}

1. 1 : la barre horizontale des deux A a été omise; I. 2 : la barre horizontale du premier $\mathrm{A}$ a été omise. $\mathrm{G}$ à barre tombante. $\mathrm{S}$ oblique. Deuxième $\mathrm{A}$ à barre tombante.

Le nom Appius Augustus est connu sur une stèle votive de Payerne (Canton de Vaud, Suisse) (CIL XIII, 5066).

Appia : praenomen latin également usité comme cognomen (Kajanto, 1965, p. 40 et 172), connu en Gaule à Lyon (Rhône) (CIL XIII, 1832 et 2120) et à Cologne (Rhénanie-Westphalie, RFA) (CIL XIII, 8366).

Augusta : cognomen latin (Kajanto, 1965, p. 61 et 316), connu en Gaule à Bordeaux (Gironde) (CIL XIII, 652), à Osterburken (Bade-Wurtemberg, RFA) (CIL XIII, 6571 et 6586 a), à Mayence (Rhénanie-Palatinat, RFA) (CIL XIII, 6741), au nord de Strasbourg (Bas-Rhin) (CIL XIII, 6024) et à Metz

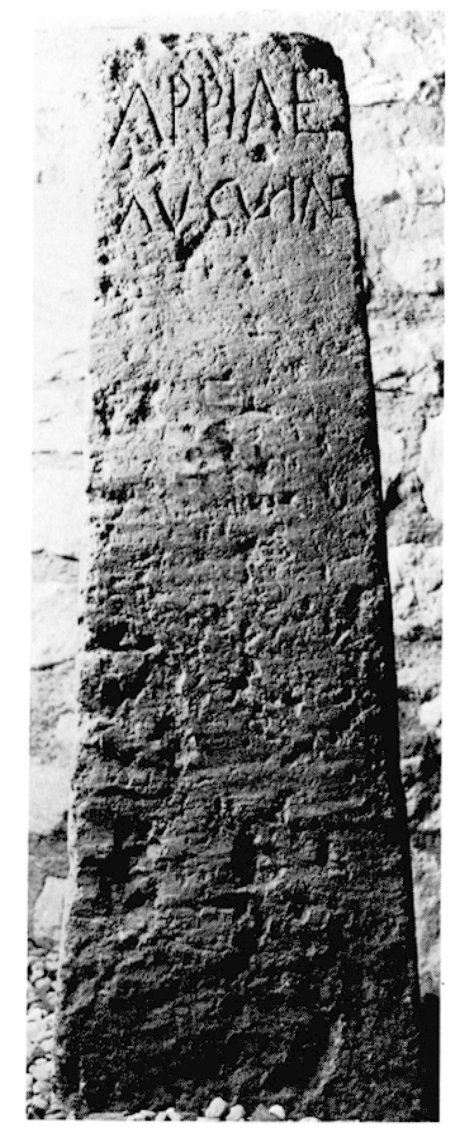

(Moselle) (Wuilleumier, 1963, $\mathrm{n}^{\circ}$ 372). Contrairement à l'affirmation de Lejay, Augustus est un cognomen courant en Gaule : il est mentionné dix-neuf fois dans le tome XIII du CIL. On le trouve essentiellement dans le quart nord-est de la Gaule et en Germanie.

Musée archéologique de Dijon, inv. 234.

Belloguet, 1851, p. 96 - Rossignol, 1854, p. 569 - Caumont, 1870, p. 521 - Lejay, 1889 , $\mathrm{n}^{\circ} 139$ - Mowat, 1890, p. 416, no 28 - Calal. Musée CACO, $\mathrm{n}^{\circ} 234$ - CIL XIII, 5492.

32 Découvert au lieu-dit En Susenot, parcelle no 26 de l'ancien cadastre, actuellement rue Marivaux, vers le 18 mars 1931, lors de l'installation d'un égout. Au cours des mêmes travaux, on a mis au jour le pyramidion $\mathrm{n}^{\circ} 34$, un fragment de monument funéraire inscrit (Joubeaux, 1985) et des fragments de sculpture qui pourraient également provenir d'un monument funéraire.

Pyramidion grossièrement taillé et très érodé. Petite cuvette $(10 \times 6 \mathrm{~cm})$ au sommet. Pierre calcaire. Hauteur : 109; largeur à la base : 32 ; largeur au sommet : 19 ; épaisseur à la base : 25 ; épaisseur au sommet : 18 .

Inscription sur quatre lignes. L'écriture se dégrade progressivement de la première à la quatrième ligne. Gravure usée mais qui parait avoir été large et profonde. Hauteur des lettres : 5,5 à $10,5 \mathrm{~cm}$.

\section{IVLE / SELA / NIGO / DO Iule Selanigodo (?).}

I. 1 : les deux barres horizontales supérieures du E sont très courtes.

Iule : pour Iul(ia)e?

Selanigodo : on connaît Selane à Bourges (Cher) (CIL XIII, 1284). Selani se trouve à Vieil-Evreux (Eure), mais la décomposition du nom, In ia Selaniseboddu, n'est pas certaine (Evans, 1967, p. 469). Ici, les syllabes -godo, qui ne paraissent pas former un nom indépendant, complètent vraisemblablement Selani.

Musée archéologique de Dijon, sans numéro d'inventaire.

Grémaud, 1926-1932, p. 151-154 - Mém. CACO, 19, 1926-1932, p. 156. 


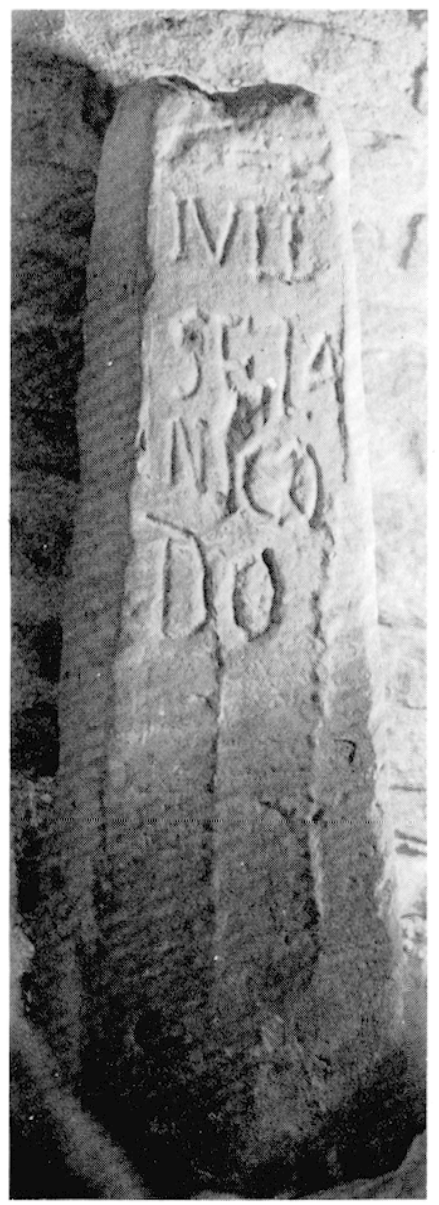

33 Découvert dans la propriété Nicolas; date, circonstances et contexte identiques à ceux du $n^{\circ} 1$.

Partie supérieure d'un pyramidion. Surface extrêmement usée. Pierre calcaire. Hauteur conservée : 45 ; largeur maximale conservée : 15,5 ; largeur au sommet : 11,5 ; épaisseur maximale conservée : 16 ; épaisseur au sommet : 13 .

Inscription sur six lignes. Écriture de très mauvaise qualité. Gravure très usée. Hauteur des lettres : 2,5 à $5,5 \mathrm{~cm}$.

\section{$\mathrm{MO} / \mathrm{RI} / \mathrm{MA} / \mathrm{NVG}$ (?) / CINTV (?) / MA Morimanug (?) Cintuma (?).}

1. 1 : les deux premières barres du $M$ ont disparu. Bien que cette ligne soit nettement séparée de la suivante, cette première syllabe nous paraît être le début du nom du défunt plutôt que l'abréviation de monumentum;

l. 2: conträirement à ce qu'affirme Lejay, la deuxième lettre ne comporte pas de barre horizontale supérieure : il ne s'agit pas d'un T;

I. 1 et $2:$ entre les lignes 1 et 2 , le $C I L$ indique une ligne supplémentaire comportant une simple barre oblique (/) qui n'est pas visible actuellement;

1. 3 : la première barre du $\mathrm{M}$ a disparu. A à longue barre tombante;

l. 4 : la troisième lettre paraît être un $\mathrm{G}$ à barre tombante coudée à angle droit plutòt qu'un $\mathrm{S}$ qui paraitrait pourtant plus logique.

La décomposition de cette inscription est incertaine et ne permet pas de faire apparaitre des noms connus par ailleurs. On peut cependant distinguer deux éléments connus dans d'autres noms gaulois : Mori- (Evans, 1967, p. 232-233) et Cintu- (Evans, 1967, p. 179-180).

Musée archéologique de Dijon, inv. 236.

Lejay, 1889, n" 70 - Catal. Musée CACO, $\mathrm{n}^{\circ} 236-$ CIL XIII, 5533.

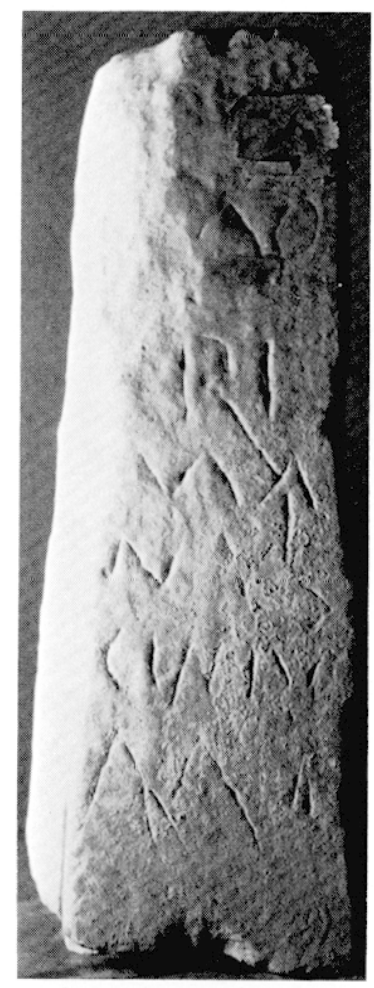

34 Découvert au lieu-dit En Susenot. Date, circonstances et contexte identiques à ceux du no 32 .

Pyramidion assez soigneusement taillé. Nombreux éclats le long des arêtes. Pierre calcaire. Hauteur : 54 ; largeur à la base : 18,5; largeur au sommet : 11,5 ; épaisseur à la base : 21 ; épaisseur au sommet : 15 .

Inscription sur six lignes. Écriture de mauvaise qualité. Gravure assez profonde pour les trois premières lignes, très superficielle pour les trois dernières. Hauteur des lettres : $1, \overline{5}$ à $3,5 \mathrm{~cm}$. 
TRIC (?) / ATVS / POTTI (?) / TRVV (?) / DOTII (?) / ATII (?)

Tricalus Polli (?) ...

1. 1: en dépit de la cassure immédiatement à sa droite, la quatrième lettre paraît complète. G. Grémaud y voyait un C, qui est effectivement la lettre qui permet de donner des deux premières lignes la lecture la plus satisfaisante;

I. 2 : A à barre oblique;

I. 3 : G. Grémaud lisait Potic. Mais, par comparaison avec la première ligne, les troisième et quatrième lettres semblent être deux $\mathrm{T}$ et la cinquième, qui est complète, un I ;

l. 4 : la quatrième lettre est au-dessus de la ligne;

I. 5 : la première lettre est très peu sûre;

I. 6 : A à barre tombante.

Les trois dernières lignes (1. 4 à 6) peut-être gravées postérieurement, paraissent dépourvues de sens: est-ce, comme le pensait G. Grémaud, la reprise maladroite des lignes 1 à 3 ?

Tricatus : ce nom ne paraît pas connu ailleurs en Gaule. On peut cependant le rapprocher des noms gaulois formés sur la racine Calu- (Evans, 1967, p. 171). Le préfixe Tri- est également usuel.

Pottus : nom connu à Trèves (Rhénanie-Palatinat, RFA) (CIL XIII, 4260); c'est aussi le nom d'un potier de Blickweiler (Sarre, RFA) travaillant à l'époque d'Antonin (Oswald, 1931, p. 245).

Musée archéologique de Dijon, sans numéro d'inventaire.

Grémaud, 1926-1932, p. 151-154-Mém. CACO, 19, 1926-1932, p. 156.

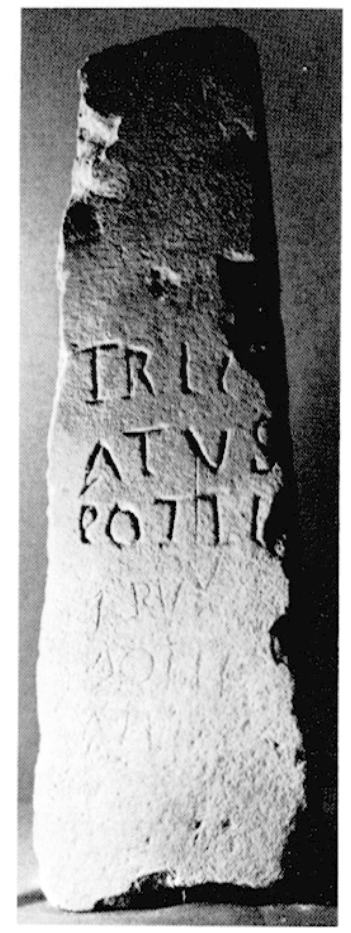

35 Découvert à l'usine à gaz du faubourg SaintPierre, au lieu-dit Les Lentillières, en avril 1899, lors de l'établissement du troisième gazomètre. Au cours des mêmes travaux, on a trouvé "dans le voisinage" une inhumation d'enfant, probablement dans un cercueil de bois ; cette sépulture, certainement galloromaine, ne peut pas être datée avec précision. La relation entre le pyramidion et la sépulture n'est pas certaine.

Fragment de pyramidion. Pierre. Hauteur conservée au moment de la découverte : 45 .

Inscription qui paraît avoir comporté au moins quatre lignes.

$$
\begin{gathered}
{[\ldots] /[\ldots] \mathrm{N} / \text { ANTONIA / } \mathrm{N}[\ldots]} \\
\ldots \text { Antonia } N . .
\end{gathered}
$$

Anlonia: nom très courant en Gaule (vingt mentions dans le tome XIII du CIL). C'est le plus souvent un gentilice.

Perdu.

Collot, 1899 - Mém. CACO, 13, 1895-1900,

p. CXLVI-CXLVII et CLXXVII - CIL XIII, 11563.

36 Découvert rue de Gray, sur le côté droit de la voie romaine de Chalon à Langres, devant la maison Masson, en septembre 1867, en creusant des tranchées d'adduction d'eau; en relation avec une sépulture par inhumation, à proximité de deux autres inhumations, dont une accompagnée d'une stèle funéraire.

Partie supérieure d'un pyramidion, assez soigneusement taillée mais érodée. Pierre calcaire. Hauteur conservée : 32 ; largeur maximale conservée : 20 ; largeur au sommet: 16,5 ; épaisseur maximale conservée : 14,5 ; épaisseur au sommet : 12.

Inscription dont quatre lignes sont conservées. Écriture de qualité moyenne; les lignes montent assez nettement. Gravure profonde. Hauteur des lettres : 4 à $5,2 \mathrm{~cm}$.

\section{BALAT / VLLLA. / MATV / [...]IS. Balalulla Matu...is.}

1. 2: le A est nettement plus grand que les autres lettres. La ligne se termine par un point rectangulaire;

I. 4 : au bord de la cassure, amorce d'une lettre qui peut être un $C$, un $G$ ou un $S$. Il faut sans doute restituer au début de la ligne, contrairement à ce qu'indique le $C I L$, une autre lettre ou une syllabe de deux lettres. La ligne se termine par un point rectangulaire.

Balalulla : ce nom peut être considéré comme 
une variante de Bellatullus, - $a$, nom fréquemment attesté en Gaule : potiers de Rheinzabern (RhénaniePalatinat, RFA), et Westerndorf (Bavière, RFA) à l'époque antonine (Oswald, 1931, p. 40), inscriptions de Genève (Canton de Genève, Suisse) (CIL XII, 2627), Tarquimpol (Moselle) (CIL XIII, 4560), environs de Trèves (Rhénanie-Palatinat, RFA) (CIL XIII, 4250) et Metz (Moselle) (Wuilleumier, 1963, $\left.\mathrm{n}^{\circ} 370\right)$.

Malu...is : les noms gaulois formés sur la racine Matu- sont fréquents (Evans, 1967, p. 228-232). On retiendra particulièrement Gallio L. Maturci sur la dédicace au dieu Segomo, perdue, provenant des Bolards (Nuits-Saint-Georges, Côte-d'Or) (CIL XIII, 2846).

Musée archéologique de Dijon, inv. 232.

L.ejay, 1889, nº 143 - Catal. Musée CACO, n" $232-$ CIL XIII, 5496-5497.

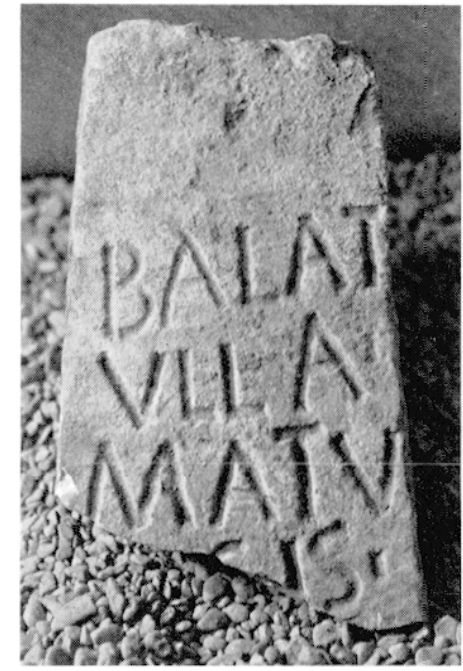

37 Découvert au lieu-dit Les Poussots. Date, circonstances et contexte inconnus.

Partie inférieure d'un pyramidion, grossièrement taillée et érodée. Des éclats sur l'arête ont endommagé la fin de l'inscription. Pierre calcaire. Hauteur conservée: 24,5 ; largeur à la base : 16; largeur minimale conservée: 13 ; épaisseur à la base: 14: épaisseur minimale conservèe : 12.

Inscription dont deux lignes sont conservées. Ecriture de mauvaise qualité. Les lignes descendent nettement. Gravure étroite et profonde. Hauteur des lettres : 2 à $2,5 \mathrm{~cm}$.

\section{SACRVNA / MARCELL[a] ou [i] Sacruna Marcella ou Marcelli.}

l. 1 : premier A à barre tombante. La dernière lettre est également un A dont la barre horizontale est placée obliquement au-dessous de la ligne; la deuxième barre oblique est visible le long de la cassure :

1. 2 : le premier $A$ est identique au deuxième $A$ de la ligne 1. E formé de deux barres verticales. Deux L à barre oblique. Le catalogue du Musée de la Commission des Antiquités de la Côte-d'Or et le $C I L$ restituent un deuxième $A$ à la fin de la ligne. L'amorce d'une seconde barre oblique n'est cependant pas visible. Il peut aussi bien s'agir d'un I légèrement incliné. Du point de vue du sens, le $\mathrm{A}$ du nominatif féminin et le I du génitif masculin sont également possibles.

Sacruna : nom connu à Langres (Haute-Marne) (CIL XIII, 5840), à Lyon (Rhône) (CIL XIII, 2028) et à Trèves (Rhénanie-Palatinat, RFA) (CIL XIII, 3641 ), où il semble que ce soit un nom masculin. Nom formé sur la racine Sacr-.

Marcellus, - $a$ : cognomen latin (Kajanto, 1965, p. 173) très courant en Gaule : Marcellus se trouve vingt-sept fois et Marcella huit fois dans le tome XIII du CIL.

Musée archéologique de Dijon, inv. 244.

Catal. Musée CACO, n $244-C I L$ XIII, 5562.

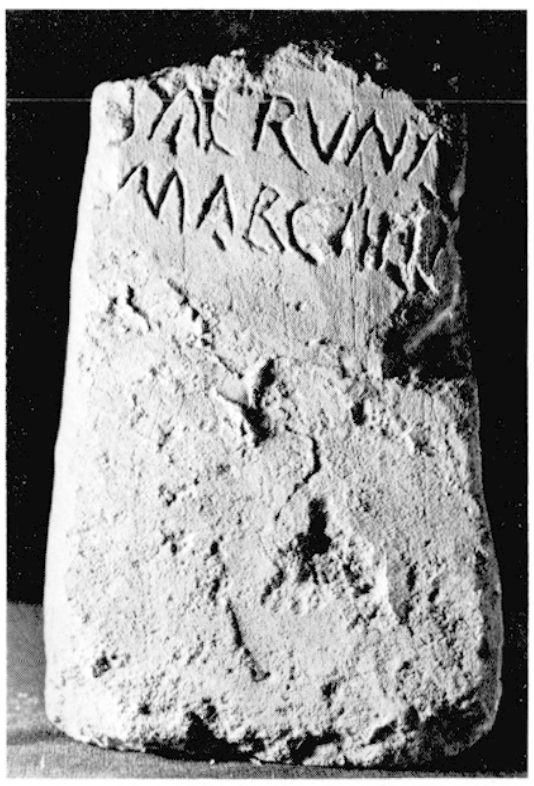

38 Découvert dans une sablière de la proprièté Giraud, située entre le chemin d'Epirey et l'usine Fouilland, au nord de La Maladière, actuellement entre les avenues de Marbotte et Aristide-Briand et la rue Maréchal-Franchet-d'Esperey; en mai 1898, 
dans des circonstances fortuites. On a découvert "à proximité" des sépultures par inhumation, avec des fragments de plusieurs autres pyramidions, anépigraphes. Le pyramidion inscrit était accompagné de deux monnaies, une d'Hadrien, l'autre non identifiee, "qui étaient collées, paraît-il, contre ce bloc par la terre comprimée" (Fourier). On a trouvé également deux vases en céramique, non conservés, dont la fonction n'a pas été déterminée.

Fragment de pyramidion soigneusement taillé. Pierre calcaire. Hauteur conservée : 14; largeur conservée sur la face inscrite: 14,5; épaisseur maximale conservée : 21 .

Inscription dont deux lignes sont conservées. Écriture de qualité moyenne. La première ligne monte de plus de $2 \mathrm{~cm}$. Gravure large et profonde. Hauteur des lettres : 4 à $4,2 \mathrm{~cm}$.

\section{[...] / [v]RBICI / .F. ... Urbici f(ilius) ou f(ilia).}

1. 1 : la cassure de la pierre laisse deviner à gauche une barre oblique qui ne peut appartenir qu'à un $\mathrm{V}$, qui est sans doute la première lettre de la ligne si l'on considère que le mot est placé symétriquement par rapport à la deuxième ligne;

l. 2: $\mathrm{F}$ accosté de deux points triangulaires.

Urbicus : cognomen latin (Kajanto, 1965, p. 81 et 311) courant en Gaule (quinze autres mentions dans le tome XIII du CIL). C'est un nom fréquent surtout dans le Nord-Est de la Gaule : on notera particulièrement sa présence à Langres (HauteMarne) (CIL XIII, 5693 et 5875) et Essarois (Côted'Or) (CIL XIII, 5644).

Musée archéologique de Dijon, sans numéro d'inventaire.

Fourier, 1898 - Mém. CACO, 13, 1895-1900,

p. CIV (Fourier) - CIL XIII, 11571 a.

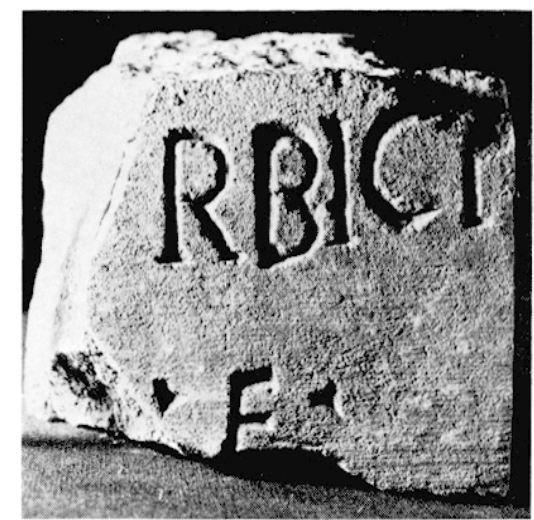

39 Découvert au lieu-dit Les Poussots, en 1875. Circonstances et contexte inconnus.

Pyramidion portant des traces de scie, surtout sur les faces latérales. Pierre calcaire. Hauteur : 74; largeur à la base : 23 ; largeur au sommet : 13,5; épaisseur à la base et au sommet : 11,5.

Sur la face principale est gravée une ascia (hauteur : $21,5 \mathrm{~cm}$ ).

Musée archéologique de Dijon, inv. 1887.

Calal. Musée CACO, n 1887 - Mém. CACO, 12, 1889-1895, p. LXXXIII.

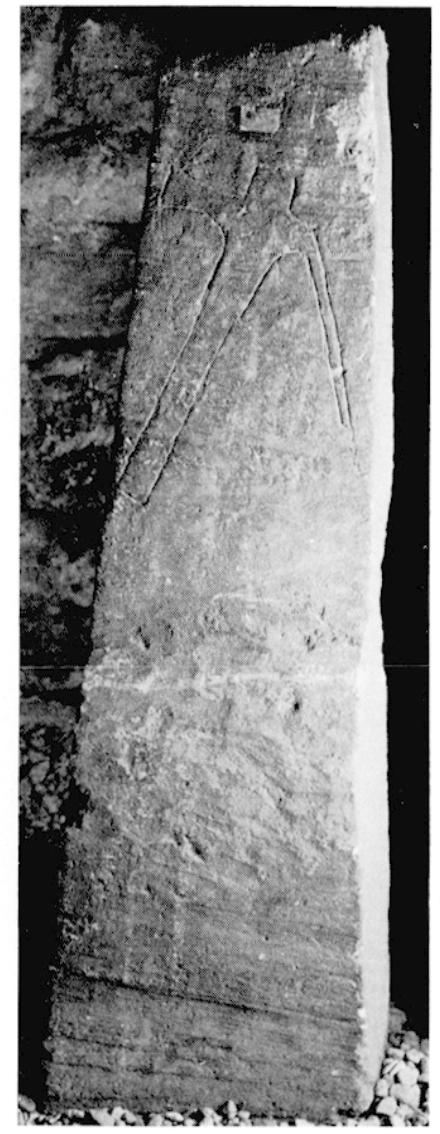

\section{ÉPIGRAPHIE}

Outre les trente-neuf monuments inscrits inventoriés ci-dessus, des pyramidions anépigraphes ont été découverts dans la nécropole gallo-romaine de Dijon. Beaucoup étant simplement signalés dans des comptes rendus de fouilles anciens, ils ne peuvent être dénombrés avec précision.

Lorsqu'elles existent, les épitaphes sont généralement brèves (cf. tableau ci-contre). Elles peuvent comporter uniquement un nom propre, certainement celui du défunt. Dans les autres cas, les formules 
TABIFAU I : TYPOLOGIF DES ÉPITAPHES

\begin{tabular}{|c|c|c|}
\hline Formule funéraire & $\begin{array}{l}\text { Cas du nom de } \\
\text { personne }\end{array}$ & $\begin{array}{l}\mathrm{n}^{\circ} \text { du } \\
\text { catalogue }\end{array}$ \\
\hline Nom de personne seul & $\begin{array}{l}\text { Nominatif } \\
\text { Datif } \\
\text { Indéterminé }\end{array}$ & $\begin{array}{l}34 \\
31 \\
32,33 \\
\end{array}$ \\
\hline $\begin{array}{l}\text { Monumentum (ou abréviation) } \\
+ \text { nom de personne }\end{array}$ & $\begin{array}{l}\text { Nominatif } \\
\text { Génitif } \\
\text { Indéterminé }\end{array}$ & $\begin{array}{l}21,27(?), 28 \\
19,20,25 \\
26,29,30 \\
22,23,24\end{array}$ \\
\hline Dis Manibus + nom de personne & Indéterminé & 1 \\
\hline$D . M .+$ nom de personne & $\begin{array}{l}\text { Nominatif } \\
\text { Datif } \\
\text { Indéterminé }\end{array}$ & $\begin{array}{l}3,5 \\
6 \\
2,4,7 \\
\end{array}$ \\
\hline M.D. + nom de personne & $\begin{array}{l}\text { Nominatif } \\
\text { Indéterminé }\end{array}$ & $\begin{array}{l}8 \\
9 \\
\end{array}$ \\
\hline D. + nom de personne & Nominatif & 10 \\
\hline D.M.Memo (?) + nom de personne & Génitif (?) & 11 \\
\hline $\begin{array}{l}\text { Dis Manibus + Monumentum + } \\
\text { nom de personne }\end{array}$ & Génitif & $12-13$ \\
\hline $\begin{array}{l}\text { D. M. }+ \text { Monumentum } \\
\text { (ou abréviations) } \\
\text { + nom de personne }\end{array}$ & $\begin{array}{l}\text { Génitif } \\
\text { Indéterminé }\end{array}$ & $\begin{array}{l}15,16 \\
14\end{array}$ \\
\hline $\begin{array}{l}\text { M. D. + Monumentum + nom } \\
\text { de personne (?) }\end{array}$ & Indéterminé & 18 \\
\hline $\begin{array}{l}\text { D. }+ \text { Monumentum }+ \text { nom } \\
\text { de personne (?) }\end{array}$ & Indéterminé & 17 \\
\hline
\end{tabular}

Pour les $n^{\circ *} 35$ à 38 , l'épitaphe est trop incomplète pour être intégrée à ce tableau.

funéraires se résument à des variations sur deux éléments de base: Dis Manibus et Monumentum. Lorsque ce dernier est réduit au $M$ initial, on pourrait également restituer M(anibus) ou $M$ (emoriae), mais il faut remarquer qu'on ne connaît pas d'exemple local d'un de ces deux mots précédant seul et en toutes lettres le nom du défunt.

Dis Manibus est extrêmement courant à Rome comme dans toute la Gaule, que ce soit sous sa forme complète ou abrégée. Monumenlum est le terme qui, en latin classique, désigne "tout ce qui est destiné à perpétuer la mémoire d'une personne ou d'une chose. Ce nom s'applique (...) particulièrement à un monument funéraire. ${ }^{26}$. Il n'est d'ailleurs pas rare de voir le tombeau appelé monumentum dans les épitaphes de Gaule, en particulier dans les formules du type $H(o c) M$ (onumentum) H(eredem) $N($ on) $S$ (equelur). Mais l'usage d'une épitaphe comportant simplement le mot monumentum suivi du nom du défunt et

26 Daremberg, Saglio, 1874-1919, article Monumentum, III, 2, p. 1997. éventuellement précédé de $D($ is ) $M$ (anibus) paraît particulier aux monuments dijonnais : on en relève vingt-six exemples à Dijon dans le tome XIII du $C I L$, seize autres dans un rayon d'une centaine de kilomètres autour de Dijon, en particulier sur les territoires des Lingons, des Mandubiens et des Séquanes, et seulement sept dispersés dans les autres régions de Gaule. A Dijon, ce terme est plus fréquemment utilisé sur les pyramidions que sur les stèles.

En l'absence de toute formule, c'est le type même du monument et le lieu de son implantation qui pouvaient en affirmer le caraclère funéraire. Dans un seul exemple ( ${ }^{\circ} 31$ ), l'utilisation du datif pourrait avoir le sens de "à la mémoire de...". Lorsque le mot monumentum est utilisé, il rend explicite la destination de la pierre. Le génitif qui le suit le plus souvent doit peut-être être interprété comme une forme simplifiée des formules qui précisent que le monument reste la propriété du défunt. L'utilisation de la formule $D($ is ) $M$ (anibus) semblerait donner à l'épitaphe une signification religieuse plus marquée. Cependant, l'absence de lien syntaxi- 
que entre la formule et le nom du défunt - on trouve quatre noms propres au nominatif pour un au datif et cinq cas indéterminés - et l'utilisation presque constante de la forme abrégée D.M., avec parfois l'inversion des deux lettres ou la suppression de la seconde, permettent de penser que le sens réel de la formule n'était pas toujours compris : elle pouvait alors, tout comme monumentum, signifier simplement le caractère funéraire de l'inscription.

Les épitaphes gravées sur les pyramidions ne comportent en général pas d'autre élément que la formule et le nom du défunt. On pourrait seulement citer deux exemples d'épitaphes mentionnant peutêtre le nom du curateur chargé de faire exécuter le monument ( ${ }^{\circ s} 11$ et 16). Mais il s'agit dans les deux cas d'inscriptions perdues et certainement mal relevées: sur l'inscription $\mathrm{n}^{\circ} 11$, on ne peut pas exclure qu'il s'agisse d'une seconde épitaphe. Il est d'ailleurs remarquable que les pyramidions ne portent que très exceptionnellement une épitaphe commune à deux défunts ( $\mathrm{n}^{\circ} 15$, mais il s'agit là encore d'un exemple incertain), alors que cette particularité est courante sur les stèles figurées dijonnaises.

Cette brièveté des épitaphes se retrouve sur les stèles funéraires dijonnaises comme d'ailleurs sur celles de Franche-Comté (Walter, 1974, p. 163-165) ou de Langres même si, dans ce dernier cas, la mention du curateur est beaucoup plus fréquente. Dans le Centre-Est de la Gaule, seules les épitaphes de quelques grands monuments sont un peu plus développées.

En dépit de leur sécheresse, ces inscriptions fournissent un certain nombre d'indications chronologiques, en particulier grâce aux formules funéraires. La formule Dis Manibus écrite intégralement serait caractéristique, en Gaule, de la seconde moitié $d u{ }^{\text {er }} s$. avec quelques exemples dans la première moitié du $\mathrm{II}^{\mathrm{e}}$, alors que l'abréviation D.M. apparaîtrait vers la fin du $\mathrm{I}^{\text {rr }} \mathrm{s}$. et serait courante au II ${ }^{\circ} .{ }^{27}$. Monumenlum, associé à Dis Manibus comme à $D . M$., a vraisemblablement connu la même période d'utilisation, seconde moitié du $\mathrm{r}^{\mathrm{er}} \mathrm{s}$. et $\mathrm{Ir}^{\mathrm{r}} \mathrm{s}$. Mais il n'est pas possible de savoir si son utilisation se prolonge au delà du II" $\mathrm{s}$. On peut seulement remarquer que le mot est souvent abrégé, parfois réduit au $\mathrm{M}$ initial. Doit-on considérer que, comme pour Dis Manibus, cette abréviation est la marque d'une date plus tardive? Il faut cependant noter que les formules dont on considère l'usage postérieur au

27 Sur la chronologie des formules funéraires en Gaule. voir essentiellement Hatt (1951, p. 19) et Audin, Burnand (1959).
II $^{*}$ s. sont très rares à Dijon. Parmi les pyramidions, seul le $n^{\circ} 11$, si l'on doit bien y restituer la formule $D$ (is) M(anibus el) Memo(riae), pourrait être daté de la fin du $\mathrm{II}^{\circ}$ ou du $\mathrm{III}^{\prime} \mathrm{s}$. Par ailleurs, la brièveté même des inscriptions, réduites dans quelques cas à un simple nom au datif ou au nominatif, pourrait être l'indice d'une date précoce, si l'on considère qu'à Lyon ce type d'épitaphe est très rare après 70 après J.-C. Plutôt qu'une utilisation prolongée des types d'épitaphes en usage au 11 " s., il semble qu'il y ait eu à Dijon une raréfaction des monuments funéraires à partir du ${ }^{\prime \prime}{ }^{\circ}$ s. : la sculpture funéraire locale paraît en effet dater, pour l'essentiel, du Ir $^{\prime \prime}{ }^{28}$ et le secteur utilisé pour les sépultures dijonnaises du Bas-Empire n'a livré aucun monument funéraire des $11 \mathrm{I}^{\circ}$ et $\mathrm{IV}^{\circ} \mathrm{s}$. (Joubeaux, $1981 ; 1984-1985)$ ).

La qualité de l'écriture est très variable. Il s'agit toujours d'une écriture capitale mais qui, même dans les exemples les plus soignés $\left(n^{0 s} 1,7,17\right)$, caractérisés par la régularité des dimensions et de l'espacement des lettres et la profondeur de la gravure, n'atteint jamais la perfection de la grande écriture monumentale. Les plus médiocres présentent au contraire des lettres mal formées, irrégulières et, dans quelques cas difficilement lisibles ( $\mathrm{n}^{\text {\%s }} 24,27$, 33). Certaines lettres comportent des particularités que l'on retrouve sur plusieurs inscriptions :

$\Lambda=\wedge\left(\mathrm{n}^{\mathrm{N}} \mathrm{2}, 6,19,27,31\right) ; \Lambda=\uparrow$, 个 $\left(\mathrm{n}^{\mathrm{n} *} 2,11\right.$, $13,16,29,31,34,37)$.

$\mathrm{E}=\|\left(\mathrm{n}^{\mathrm{os}} 6,7(?), 13,14,16,19,21,24,37\right)$. $F=I^{\prime}\left(n^{\circ} 27\right) . G=G\left(n^{\circ} 21,29\right) . L=L, ~$ $\left(\mathrm{n}^{\mathrm{n}: 6} 6,13,19,25,29,37\right)$.

Les épitaphes ne comportant que peu de mots, les abréviations sont rares, en dehors de celles portant sur Dis Manibus et Monumentum, étudiées plus haut. On trouve seulement filius, - $a$ abrégé en fil $\left(\mathrm{n}^{\circ \mathrm{0}} 5,11\right), f i\left(\mathrm{n}^{\circ} 10\right)$ ou $f\left(\mathrm{n}^{\circ} 38\right)$, et, curieusement, quelques noms propres dont la désinence est supprimée $\left(n^{\circ s} 2,4,15\right)$. Il n'existe que trois cas certains de ligature $\left(n^{\circ *} 17,27,30\right)$. D'une manière générale, les mots sont correctement séparés, soit par un changement de ligne, soit par un espace; les séparations sont parfois soulignées par des points ronds $\left(n^{0 *} 28\right.$ - le point est placé à l'intérieur du (,- 29$)$, rectangulaires $\left(\mathrm{n}^{\circ} 36\right)$ ou triangulaires $\left(\mathrm{n}^{\circ} 38\right)$. Mais il existe quelques exemples de graphie continue $\left(\mathrm{n}^{\circ} 5\right.$, I. $3 ; n^{\circ} 11$, I. $3 ; n^{\prime \prime} 21$, I. $4 ; n^{\prime \prime} 29$, I. 3). Par ailleurs, la forme étroite des pyramidions a très fréquemment obligé les graveurs à répartir sur plusieurs lignes les mots les plus longs.

28 Deyts, 1971, p. 356 et Deyts, 1976, chapitre "présentation générale des sculptures". 
En dehors des exemples cités plus haut d'absence de lien syntaxique entre la formule funéraire et le nom du défunt, on ne relève que deux fautes d'accord : un datif pour un génitif $\left(n^{\circ} 6,1.3\right)$ et un nominatif pour un génitif $\left(\mathrm{n}^{\circ} 16,1.4\right)$ Quant aux fautes d'usage, elles concernent toutes le mot monumentum: le premier $\mathrm{U}$ est presque toujours remplacé par un I ( ${ }^{\text {os }} 13$ (?), 14, 21, 22, 24, 25, 26 (?), 27) ou supprimé $\left(\mathrm{n}^{\mathrm{os}} 17,19\right)$; la fréquence de ces deux graphies permet de penser qu'elles correspondent à une prononciation locale particulière. On trouve aussi deux exemples du E remplacé par un I $\left(\mathrm{n}^{\text {os }} 21\right.$, $25)$ et une étonnante désinence en $O\left(n^{\circ} 21\right)$. Le seul exemple de graphie normale est douteux $\left(\mathrm{n}^{\circ} 20\right)$.

$\mathrm{Si}$, d'une manière générale, les difficultés de lecture de ces inscriptions sont assez peu importantes, c'est leur brièveté même et les incertitudes de la syntaxe qui rendent parfois difficile une interprétation précise.

\section{ONOMASTIQUE}

Sur les cinquante-trois éléments de noms de personnes relevés sur les pyramidions dijonnais, vingt-cinq sont d'origine latine (d'après Kajanto, 1965) même si certains, tels Iule ( $\left.{ }^{\circ} 32\right)$ ou Maxminia ( $\left.\mathrm{n}^{\circ} 28\right)$, prennent une forme particulière, et vingttrois peuvent être considérés comme des noms d'origine celtique ${ }^{29}$; trois sont trop incomplets et un autre est de lecture trop incertaine pour être attribués à l'une ou l'autre origine ${ }^{30}$. Enfin, Petrullus ( $\left.{ }^{\circ} 13\right)$, considéré par Kajanto comme un nom latin, pourrait également avoir une origine celtique.

29 D'après Holder (1896-1907), Dottin (1920), Evans (1967) et Whatmough (1970). Nous y avons ajouté quelques noms qui n'apparaissent pas dans les listes établies par ces différents auteurs mais qui ne sont pas des cognomina latins.

30 Voir index onomastique p. 242.

Tableau II : SystèmEs dE DÉNOMINATION

\begin{tabular}{|c|c|c|}
\hline \multicolumn{3}{|l|}{ Nom simple } \\
\hline & $\begin{array}{l}\text { Magianus } \\
\text { Iulius (?) } \\
\text { Annicenus (?) } \\
\text { Tillicus } \\
\text { Iunianus }\end{array}$ & $\begin{array}{c}4 \\
8 \\
16 \\
25 \\
30\end{array}$ \\
\hline \multicolumn{3}{|c|}{ Nom + indication de filiation } \\
\hline Filius, - $a$ indiqué & $\begin{array}{l}\text { Rebrica Sedati filia } \\
\text { Regalis A...ter...li filius } \\
\text { Carantinus ... filius } \\
\text { Privatus Arrici filius (?) } \\
\text { Paulianus Pauli filius } \\
\text { Satrio Severini filius } \\
\text {... Urbici filius }\end{array}$ & $\begin{array}{c}5 \\
6 \\
10 \\
11 \\
16 \\
27 \\
38\end{array}$ \\
\hline Filius, $-a$ sous-entendu & $\begin{array}{l}\text { Cacudia Suadugeni filia } \\
\text { Tricatus Potti filius }\end{array}$ & $\begin{array}{l}21 \\
34 \\
\end{array}$ \\
\hline $\begin{array}{l}\text { Filius, - } a \text { sous-entendu } \\
\text { ou disparu }\end{array}$ & $\begin{array}{l}\text { Maxminia Mo...ui filia } \\
\text { Balatulla Matu...is filia }\end{array}$ & $\begin{array}{l}28 \\
36 \\
\end{array}$ \\
\hline \multicolumn{3}{|c|}{ Nom composés de deux éléments, sans indication de filiation } \\
\hline Nom masculin & Avitianus Dribionos (?) & 2 \\
\hline Nom féminin & Appia Augusta & 31 \\
\hline \multicolumn{3}{|c|}{$\begin{array}{l}\text { Nom composés de deux éléments, système de dénomination } \\
\text { indéterminé }\end{array}$} \\
\hline $\begin{array}{l}\text { Deux éléments au } \\
\text { genitif }\end{array}$ & $\begin{array}{l}\text { Roxtanus Petrullus ou } \\
\text { Petrulli filius } \\
\text { Lepidus Lippo ou Lipponis filius } \\
\text { Litugenus Biracatus ou } \\
\text { Biracati filius }\end{array}$ & $\begin{array}{l}13 \\
26 \\
29 \\
\end{array}$ \\
\hline $\begin{array}{l}\text { Deux éléments, au moins } \\
\text { un cas indéterminé }\end{array}$ & $\begin{array}{l}\text { Hilarus D... ou D... filius } \\
\text { Flavinus Nantillus ou } \\
\text { Nantilli filius } \\
\text { Iulia Sollemnis ou Sollemnis filia } \\
\text { Iunianus Ox... ou Ox... filius } \\
\text { Sacruna Marcella ou Marcelli filia }\end{array}$ & $\begin{array}{l}3 \\
\\
15 \\
19 \\
20 \\
37 \\
\end{array}$ \\
\hline $\begin{array}{l}\text { Deux éléments, cas et } \\
\text { genre indéterminés }\end{array}$ & $\begin{array}{l}\text { Iule Selanigodo (?) } \\
\text { Morimanug Cintuma (?) }\end{array}$ & $\begin{array}{l}32 \\
33 \\
\end{array}$ \\
\hline
\end{tabular}

Les autres noms sont trop incomplets pour ètre intégrés à ce tableau. 
La proportion des noms celtiques sur les pyramidions est donc proche de $50 \%$ alors que, dans son étude globale des noms indigènes sur les épitaphes de Gaule des trois premiers siècles, M. J.-J. Hatt pouvait classer Dijon dans le groupe des villes où la proportion se situait entre 25 et $40 \%$ (Hatt, 1951, p. 28). Une estimation basée sur l'ensemble des épitaphes dijonnaises répertoriées dans le $C I L$ permet en effet d'observer que les noms gaulois sont à peu près deux fois moins nombreux que les noms latins sur les autres types de monuments funéraires.

Il faut remarquer toutefois que lorsque le nom d'un individu est constitué de deux éléments, ce qui est le cas le plus fréquent, toutes les combinaisons sont possibles: les deux éléments peuvent ètre gaulois ( $\left.\mathrm{n}^{\text {os }} 21,29,33,34,36\right)$ ou latins ( $\mathrm{n}^{\text {os }} 16,19,26$, 27 ); le premier peut être gaulois et le second latin $\left(\mathrm{n}^{\text {os }} 5,37\right)$ ou le premier latin et le second gaulois $\left(\mathrm{n}^{\text {os }} 2,15,20,28\right)$. Le tableau des systèmes de dénomination montre que dans de nombreux exemples la relation qui unit les deux éléments est impossible à déterminer, ce qui est particulièrement gênant pour l'interprétation des noms composés d'éléments d'origines différentes. On peut seulement remarquer que lorsque filius est indiqué, les noms identifiables sont presque tous latins (seul le $n^{\circ} 5$ comporte un individu au nom gaulois dont le père porte un nom latin). Au contraire, lorsque filius est sous-entendu, les noms identifiables sont presque tous gaulois (seul le $n^{0} 28$ comporte un individu au nom latin dont le père porte un nom gaulois). Le nom du père et celui du fils ou de la fille paraissent le plus souvent avoir la même origine.

Même en tenant compte des lectures incertaines ou suspectes, on constate que la moitié environ des noms gaulois, même s'ils se rattachent à une racine connue, apparaissent ici sous une forme qui n'a pas été relevée ailleurs en Gaule. Les noms d'origine latine sont au contraire pour la plupart extrêmement communs en Gaule. En règle générale, lorsque ces noms, gaulois ou latins, sont connus sur d'autres inscriptions de Gaule, celles-ci sont particulièrement concentrées dans le quart nord-est, entre Lyon et la vallée du Rhin.

\section{ICONOGRAPHIE}

Les pyramidions portant une représentation figurée sont très rares. Parmi ceux de Dijon, seul le $\mathrm{n}^{\circ} 39$, anépigraphe, porte la représentation d'une ascia. Il faut également signaler un pyramidion aujourd'hui perdu sur lequel auraient été représentées deux petites figures d'enfants ${ }^{31}$.

En dehors du cadre de notre étude, nous ne connaissons qu'un exemple de pyramidion figuré : il provient de Langres et comporte, au-dessous de l'épitaphe, la représentation d'une palme entre deux feuilles ${ }^{32}$.

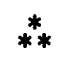

\section{CLIENTELLE DES PYRAMIDIONS}

On ne peut esquisser qu'un portrait bien flou des défunts dont la sépulture était signalée par un pyramidion. L'iconographie pratiquement inexistante, l'épigraphie très peu développée, les rares renseignements sur les sépultures auxquelles ces monuments étaient associés n'apportent que peu d'indications sur l'origine ethnique, le statut social ou les croyances religieuses des défunts.

La proportion importante de noms de souche gauloise sur les pyramidions paraît marquer l'attachement de la population indigène à ce type de monument. Mais en l'absence de représentation des défunts et de toute mention relative à leur profession ou à leurs éventuelles fonctions honorifiques, on ne possède aucun renseignement explicite sur leur statut social. Ces silences peuvent être en eux-mèmes l'indication d'une situation modeste. Par ailleurs, le type même du monument permet de supposer que la clientèle qui lui était attachée était assez pcu fortunée. Les pyramidions étaient certainement moins onéreux que les stèles à personnages et, $a$ fortiori, que les grands monuments ornés. On peut penser que si de riches défunts étaient restés fidèles par tradition à ce type de monument, ils l'auraient fait évoluer vers des variantes plus "architecturales" et plus ornées. Il convient peut-être cependant de nuancer cette hypothèse sur le degré de fortune des défunts en tenant compte de la dimension de certains pyramidions (plus de $2 \mathrm{~m}$ pour ceux de Mesmont et d'Alise-Sainte-Reine), de la qualité parfois très bonne, par rapport au contexte régional, des inscriptions et du fait qu'à une seule sépulture pouvaient être associés plusieurs pyramidions $\left(n^{o s} 12-13\right)$. On peut penser par ailleurs que les défunts les plus pauvres pouvaient ne pas posséder de monument de pierre.

31 Mém. CACO, 14, 1901-1905, p. clxxx. Avec quelques autres, ce pyramidion servait de boute-roue dans la cour d'un bâtiment proche de l'usine à gaz, à Dijon.

32 CIL XIII, 5820; Espérandieu, 3299. 
Pour ce qui concerne les croyances religieuses, on ne possède également que quelques indications ténues. Celles fournies par l'onomastique sont rares et souvent peu sûres. Le cognomen Hilarus $\left(\mathrm{n}^{\circ} 3\right)$ pourrait être celui d'un adepte du culte de la Grande Mère (Hatt, 1951, p. 43-62 et 251-292). Dans sa liste des cognomina religieux, M. J.-J. Hatt cite également l'inscription $\mathrm{n}^{\circ} 6$ à propos du cognomen Aster, mais la lecture de ce nom nous parait trop incertaine pour être retenue. Incertains également sont les rapports entre Satrio $\left(\mathrm{n}^{\circ} 27\right)$ et Saturio ou entre Selanigodo $\left(\mathrm{n}^{\circ} 32\right)$ et Selane. On ne peut retenir, parmi les autres éléments que comportent les épitaphes, que les nombreuses mentions des Dieux Mânes, mais elles font référence au culte des morts et non à celui des divinités infernales et nous avons vu que le sens précis de la formule ne parait pas avoir été toujours clairement compris. Reste l'unique représentation de l'ascia dont l'interprétation mystique paraît, en l'état actuel de nos connaissances, moins bien étayée que l'argumentation en faveur d'une signification rituelle ${ }^{33}$.

\section{HYPOTHĖSES SUR L'ORIGINE DES PYRAMIDIONS}

Cette concentration dans les nécropoles dijonnaises d'un type de monument funéraire particulier a été observée de longue date (Bull. Mon., 20, 1854, p. 568-570) et deux hypothèses contradictoires ont été élaborées pour l'expliquer.

La première, proposée par E. Linckenheld, considère les pyramidions dijonnais comme les dérivés d'un type d'origine celtique, la "stèlemaison" (Linckenheld, 1927, p. 56). Malheureusement, E. Linckenheld n'avait pas pu examiner luimême les monuments dijonnais et ses arguments reposent en fait sur une lecture erronée du CIL. L'influence des stèles-maisons serait en effet démontrée par l'existence de deux monuments dijonnais dont la base serait évidéc, cc qui est, pour E. Linckenheld, un des éléments caractéristiques et essentiels des stèles-maisons. Or, l'expression stela excavata utilisée par le $C I L$ pour désigner ces deux monuments (CII, XIII, 5495 et 5498) indique non pas des pyramidions à base évidée, mais des stèles

33 Sur le sens rituel - consécration et inviolabilité de la tombe - ou symbolique - "signe mystique figurant la vie éternelle" - de l'ascia, voir Ilatt. 1951, p. 85-107. avec une niche abritant la représentation du défunt. Par ailleurs, aucun des pyramidions dijonnais ne possède une base évidée.

S'opposant à cette théorie d'une origine indigène, M. J.-J. Hatt y voit "un type d'origine romaine qui serait parvenu chez les Lingons soit par Lyon et la vallée de la Saône, soit par Langres, un des centres gallo-romains où l'influence de l'Italie est la plus sensible" (Hatt, 1951, p. 215). Cependant, le seul exemple lyonnais cité par M. J.-J. Hatt (Espérandieu, III, 1785) est un objet difficile à identifier. Son caractère funéraire n'est pas absolument certain et il est incomplet à la base : il pouvait donc n'être, comme le suggérait E. Espérandieu, qu'un élément d'un monument plus important. Dans son état actuel d'ailleurs, sa forme est plus pyramidale que celle des exemplaires dijonnais et les deux lettres qui y sont gravées (B.F. pour beneficiarius) laissent penser qu'un texte plus complet a aujourd'hui disparu. Il faut remarquer surtout que cet objet n'est comparable à aucun autre monument funéraire lyonnais et que ces monuments appartiennent à des types si différents de ceux connus à Dijon qu'il ne semble pas qu'il y ait eu entre ces deux centres d'influence notable dans ce domaine.

Les quatre exemples langrois sont au contraire, nous l'avons dit, tout à fait comparables aux pyramidions dijonnais. Il faut donc très vraisemblablement les rattacher à cette série, mais faut-il en faire des prototypes? Certes, l'épitaphe au datif de trois d'entre eux permettrait, d'après les critères proposés par M. J.-J. Hatt (Hatt, 1951, p. 19), de les dater du courant du $\mathrm{I}^{\mathrm{er}} \mathrm{s}$, ce qui en ferait les contemporains des exemplaires dijonnais les plus précoces. Mais le petit nombre de pyramidions connus à Langres par rapport à ceux de Dijon incite à la réserve en ce qui concerne leur rôle de modèle. Même si l'on admet que les exemplaires langrois ont eu un rôle de prototype, il resterait par ailleurs à démontrer qu'ils ont eux-mêmes subi l'influence d'un modèle extérieur.

Il faut remarquer, ètant donné l'extrême simplicité de ce type de monument, que, pour conclure à une influence ètrangère, il faudrait non seulement montrer l'existence d'objets comparables dans une autre région à une époque immédiatement antérieure, mais également expliquer par quel cheminement ils ont pu parvenir dans la région lingone. On connaît par exemple dans la basse vallée du Rhône, au $\mathrm{I}^{\mathrm{er}} \mathrm{s}$. avant J.-C., des monuments funéraires dont la forme est proche de celle des pyramidions et qui portent une brève inscription, souvent en caractères grecs, dont l'élément essentiel est, comme sur les monu- 
ments dijonnais, le nom du défunt ${ }^{34}$. Mais nous n'avons pas, le long de l'axe Rhône-Saône les jalons qui permettraient de relier les deux groupes. Au contraire, les monuments funéraires lyonnais constituent, nous l'avons vu, un obstacle important. Par ailleurs, il est possible que les monuments funéraires du Midi aient connu des antécédents pré- et protohistoriques indigènes (Jannoray, 1955, p. 229). Dans ce cas, ce serait simplement l'usage d'une inscription funéraire qui constituerait un apport extérieur et non l'érection même d'un "monument".

Il en est peut-être de même dans la région dijonnaise. Il semble en effet que l'usage de marquer l'emplacement des sépultures ait été connu dans le Centre-Est de la Gaule à l'époque protohistorique, même si les monuments pouvaient être constitués souvent de matériaux périssables ${ }^{35}$. L'exemple le plus intéressant, tant par sa situation géographique que par sa ressemblance avec les pyramidions, est un bloc quadrangulaire en calcaire (hauteur : $80 \mathrm{~cm}$; largeur : $60 \mathrm{~cm}$; épaisseur : $30 \mathrm{~cm})$ implanté au centre d'un enclos funéraire daté de La Tène II, à Vix (Côte-d'Or) ${ }^{36}$.

Si l'on considère la concentration de ces monuments à Dijon, accompagnée de quelques exemples satellites dans un rayon de cent kilomètres, et la fréquence de l'usage du mot monumentum, essentiellement régional, sur les pyramidions; si l'on considère également que l'étude onomastique paraît montrer un attachement de la population d'ascendance gauloise aux pyramidions, on constate que l'hypothèse d'une origine locale de ce type de monuments semble la mieux étayée.

\section{Hervé Joubeaux}

34 Parmi les publications récentes, Py, 1981, p. 18; Lejeune (1977-1978).

35 Joffroy $(1976$, p. 823) à propos des tertres funéraires de l'époque de La Tène en Bourgogne : "ce n'est qu'exceptionnellement que l'établissement d'une sépulture a dérangé une tombe antérieure, ce qui laisse supposer qu'une marque apparente, un pieu de bois par exemple, indiquait l'emplacement des sépultures".

36 Gallia, 26, 1968, Informations archéologiques, Circonscription de Bourgogne (R. Martin), p. 489-490.

\section{Nota Bene}

Cet article est illustré de photographies de l'auteur à l'exception des numéros 2 (Musée des Antiquités nationales, Saint-Germain-en-Laye) et 28 (Archives départementales de la Còte-d'Or).

\begin{tabular}{|c|c|c|}
\hline Index onomastique & Nom* & $n^{\circ}$ catal. \\
\hline Annicens (?) & $?$ & 16 \\
\hline Antonia & $\mathrm{L}$ & 35 \\
\hline Appia & $\mathrm{L}$ & 31 \\
\hline Arricus & G & 11 \\
\hline Augusta & $\mathrm{L}$ & 31 \\
\hline Avitian & $\mathrm{L}$ & 2 \\
\hline A.ter.lus (?) & ? & 6 \\
\hline Balatulla & G & 36 \\
\hline Biracatus & G & 29 \\
\hline Cacudia & G & 21 \\
\hline Cambad ... (?) & G & 11 \\
\hline Carantinus & G & 10 \\
\hline Cintuma (?) & G & 33 \\
\hline Dribionos & G & 2 \\
\hline Flavinus & $\mathrm{L}$ & 15 \\
\hline Hilarus & $\mathrm{L}$ & 3 \\
\hline Iule (?) & $\mathrm{L}$ & 32 \\
\hline Iulia & L & 19 \\
\hline Iulius & $\mathrm{L}$ & 8 \\
\hline Iunianus & $\mathrm{L}$ & 20,30 \\
\hline Lepidus & $\mathrm{L}$ & 26 \\
\hline Lippo & $\mathrm{L}$ & 26 \\
\hline Litugenus & G & 29 \\
\hline Magianus & $\mathrm{L}$ & 4 \\
\hline Marcella ou Marcellus & $\mathrm{L}$ & 37 \\
\hline Matu ... & G & 36 \\
\hline Maxminia & $\mathrm{L}$ & 28 \\
\hline Mocuus, Moguus ou Mosuus & G & 28 \\
\hline Morimanug (?) & G & 33 \\
\hline Nantil ... & $\mathrm{G}$ & 15 \\
\hline$O x \ldots$ & G & 20 \\
\hline Paulianus & $\mathrm{L}$ & 16 \\
\hline Paulus & $\mathrm{L}$ & 16 \\
\hline Petrullus & $?$ & 13 \\
\hline Pottus & G & 34 \\
\hline Privatus & $\mathrm{L}$ & 11 \\
\hline Rebrica & G & 5 \\
\hline Regalis & $\mathrm{L}$ & 6 \\
\hline Roxtanus & G & 13 \\
\hline Sacruna & G & 37 \\
\hline Sage ... & G & 7 \\
\hline Satrio & $\mathrm{L}$ & 27 \\
\hline Sedatus & $\mathrm{L}$ & 5 \\
\hline Selanigodo (?) & G & 32 \\
\hline Severinus & $\mathrm{L}$ & 27 \\
\hline Sollemnis & $\mathrm{L}$ & 19 \\
\hline Suadugenus & G & 21 \\
\hline Su ... & $?$ & 1 \\
\hline Tillicus & G & 25 \\
\hline Tricatus & G & 34 \\
\hline Urbicus & $\mathrm{L}$ & 38 \\
\hline ...mer ... & $?$ & 22 \\
\hline
\end{tabular}

* L : nom d'origine latine ; $\mathrm{G}$ : nom d'origine gauloise. Les numéros renvoient à ceux du catalogue. 


\section{BIBLIOGRAPHIE}

Audin A., Burnand Y.

1959 : Chronologie des épitaphes romaines de Lyon, Revue des Etudes anciennes (REA), 61, p. 320-352.

Belloguet D. Roget de

1851 : Origines dijonnaises, Dijon.

Calal. Musée CACO

1894 : Calalogue du Musée de la Commission des Antiquités de la Côte-d'Or, sous la direction de Jules d'Arbaumont, Président de la Commission. IDijon.

Caumont A. de.

1870 : Abécédaire ou rudiment d'archéologie, ère gallo-romaine. 2 édition, Caen.

\section{Collot L.}

1899: Note sur des objets trouvés à Dijon aux Lentillières, Archives de la (ACO, manuscrit.

Daremberg Ch., Saglio E.

1874-1919: Dictionnaire des antiquités grecques el romaines, sous la direction de Ch. Daremberg, F. Saglio et E. Pottier, Paris.

\section{Desjardins E.}

1880 : Sept inscriptions inédites du cabinet de M. de Torcy, Revue Archéologique, n.s., 40, p. 135-139.

\section{Deyts $\mathrm{S}$.}

1971 : Recherches sur les ateliers de sculpture gallo-romaine dans la région de Ijijon, Revue archéologique de l'Est (RAE). XXII, p. 353-391.

1976 : Dijon, Musée archéologique. Sculplures gallo-romaines mythologiques et religieuses. Inventaire des collections publiques françaises, 20, Paris.

1982 : La sculpture funéraire, in : La nécropole gallo-romaine des Bolards, Nuits-Saint-Georges, Paris, Éd. du C.NRS, Centre régional de publication, Lyon, p. 103-119.

\section{Dottin G.}

1920 : La langue gauloise, Collection pour l'ètude des antiquités nationales, II, Paris.

Duval P.-M., Pinault G.

1986 : Recueil des inscriplions gauloises, sous la direction de Paul-Marie Duval, III, Les Calendriers (Coligny, Villardsd'Iléria), 45e suppl. à Gallia, Paris, Éd. du C.NRS.

Espérandieu E.

1907-1966: Recueil général des bas-reliefs, stalues el bustes de la Gaule romaine, Paris.

Evans D. E.

1967: Gaulish Personal Vames, Oxford.

Fourier G.

1898 : Rapport sur quelques trouvailles faites à Dijon, au nord de la Maladiere, Archives de la CACO, manuscrit.
Gaillard H., Parriat H.

1975 : L'officine céramique gallo-romaine de (iueugnon, $R A E$, XXVI, p. 307-412.

\section{Galliou P.}

1984 : L'Armorique romaine, Brasparts.

Grémaud G.

1926-1932: Vestiges gallo-romains à Dijon, Mémoires de la Commission des Antiquites de la Côte-d'Or, 19, p. 151-154.

Guénebauld $\mathrm{J}$.

1621 : Le réveil de Chyndonax, Dijon.

Hatt J.-J.

1951 : La tombe gallo-romaine: Recherches sur les inscriptions et les monuments funéraires gallo-romains des trois premiers siècles de notre ère, Paris.

Holder A.

1896-1907 : All-celtischer Sprachschatz, Leipzig.

Jannoray J.

1955 : Ensérune. Contribution à l'étude des civilisations préromaines de la Gaule méridionale, Paris.

Joffroy R.

1976 : Les civilisations de l'ige du Fer en Bourgogne, in : La Préhistoire française, II : Les civilisations néolithiques et protohistoriques de la lirance, sous la direction de Jean Guilaine.

Joubeaux $\mathrm{H}$

1981 : Note sur une stèle funéraire dijonnaise transformée en sarcophage, $R A E, 32$, p. 1333-136.

1984-1985: Les nécropoles gallo-romaines de Dijon, .Mém. CACO, 34, p. 149-169.

1985: Note sur un élément cylindrique provenant d'un monument funéraire gallo-romain de Dijon, $R A E, 36$, p. 138140.

\section{Kajanto I.}

1965: The Latin Cognomina, Commentationes humanarum litterarum, XXXVI, 2, IIelsinki.

Legouz dc Gcrland B.

1771 : Dissertation sur l'origine de la ville de Dijon et sur les antiquilés découvertes sous les murs bâtis par Aurélien, Dijon.

Lejay $\mathbf{P}$.

1889: Inscriptions antiques de la Côte-d'Or. Bibliothèque de l'École des Hautes-Études, $80^{\circ}$ fasc., Paris.

\section{Lejeune $\mathrm{M}$.}

1977-1978 : Epigraphie gauloise à Coudoux. Revue archéologique de Narbonnaise, X, 1977, p. 59-75 et XI, 1978, p. 135-142. 1982: Vote sur l'anthroponymie, in: La nécropole galloromaine des Bolards, Nuits-Saint-Georges, Paris, Éd. du C.NRS, Centre régional de publication, Lyon, p. 147-150. 


\section{Lépine $\mathrm{D}^{r}$}

1866 : Cippe trouvé aux Poussots en 1866, dessin légendé par le Dr Lépine, Archives de la CACO, manuscrit.

\section{Linckenheld $\mathrm{E}$.}

1927: Les stèles funéraires en forme de maison chez les Médiomatriques et en Gaule, Publications de la Faculté des Lettres de l'Université de Strasbourg, fasc. 38, Paris.

\section{Mowat R.}

1890 : Inscriptions de la citè des Lingons conservées à Dijon et à Langres, Revue Archéologique, s. III, 15, p. 403-423.

Oswald F.

1931 : Index of Potters' Stamps on Terra Sigillata, Margidunum.

\section{Pinette M.}

1978 : Les carrières de pierre gallo-romaines dans le Nord-Est de la France, catalogue, mémoire de Maitrise d'archéologiehistoire ancienne, Université de Dijon, dactylographié.

Py $\mathbf{M}$.

1981 : Les rites funéraires préromains de. Nìmes et de sa région, Dossiers Histoire et Archéologie, 55, p. 12-21.

\section{Reinach S.}

1917 : Catalogue illustré du Musée des Antiquités Nationales, I, Paris.

\section{Richard J.}

1585 : Antiquitatum Divionensium, et de statuis noviter Divione repertis in Collegio Godraniorum, liber., Paris.

Rossignol C.

1854 : Bulletin Monumental, 20, p. 469.

Walter $\mathbf{H}$.

1974: La sculpture funéraire gallo-romaine en Franche-Comté, Annales littéraires de l'Université de Besançon, 176, Paris.

Whatmough J.

1970 : The Dialects of Ancient Gaul, Cambridge (Massachussets).

Wuilleumier $\mathbf{P}$.

1963 : Inscriptions latines des Trois Gaules (France), $27^{\circ}$ suppl. à Gallia (réédition 1984), Paris, Éd. du CNRS. 